Research Article

\title{
Study of the Stability Control of Rock Surrounding Longwall Recovery Roadways in Shallow Seams
}

\author{
Cheng Zhu, ${ }^{1,2}$ Yong Yuan $\mathbb{D}^{1,2}$ Zhongshun Chen ${ }^{10},{ }^{1,2}$ Chaogui Meng, ${ }^{1,2}$ \\ and Shengzhi Wang ${ }^{1,2}$ \\ ${ }^{1}$ Key Laboratory of Deep Coal Resources Mining, Ministry of Education of China, China University of Mining \& Technology, \\ Xuzhou, Jiangsu 221116, China \\ ${ }^{2}$ School of Mines, State Key Laboratory of Coal Resources \& Safe Mining, China University of Mining \& Technology, Xuzhou, \\ Jiangsu 221116, China
}

Correspondence should be addressed to Yong Yuan; yy20062006@163.com and Zhongshun Chen; chenzhongshun2016@163.com

Received 18 December 2019; Revised 14 March 2020; Accepted 17 May 2020; Published 29 May 2020

Academic Editor: Francesco S. Marulo

Copyright $\odot 2020$ Cheng Zhu et al. This is an open access article distributed under the Creative Commons Attribution License, which permits unrestricted use, distribution, and reproduction in any medium, provided the original work is properly cited.

\begin{abstract}
The rock pressure appearance of longwall faces in shallow seams is generally violent, and roofs and supports are susceptible to damage during equipment extraction. Stability control of the rock surrounding longwall recovery roadways allows safe and rapid equipment extraction. Herein, via theoretical analysis, numerical simulations, and field observations, the stability control of the rock surrounding recovery roadways is studied to ensure the release of the accumulated rock pressure on the roof, the working resistance of the supports and the reasonableness of the recovery roadway support design. Pressure-relief technology is introduced to release the accumulated rock pressure before equipment extraction, and a discriminative approach is proposed to determine the breaking and articulated forms of key strata and broken blocks, respectively. On this basis, mechanical models of roof instability are established based on four key stratum structures in the overburden of shallow seams. Methods for calculating a reasonable working resistance for supports are discussed. Finally, Liangshuijing Coal Mine and Fengjiata Coal Mine are taken as research objects to evaluate the roof stability of recovery roadways based on observations of weighting characteristics. The support working resistances and reasonable recovery roadway widths under three key stratum structures are determined. Considering the time effect of plastic zone development, the support design of recovery roadways is optimized. FLAC2D software simulates the surrounding rock control effect of two support designs, and roof subsidence curves are obtained. The results show that the key to equipment extraction in shallow seams is to ensure that supports have reasonable working resistances and to improve the support of recovery roadways. The results provide a reference for the selection and extraction of supports in shallow seam faces.
\end{abstract}

\section{Introduction}

Coal seams with shallow mining depths, thin bedrock, and thick unconsolidated strata are usually defined as shallow seams $[1,2]$. Only a caving zone and a fracture zone exist above the longwall gob of shallow seams [3-6]. Many production practices show that the rock pressure in a shallow seam face is extremely high, and the roof is susceptible to bench convergence [7-11]. The plastic zone in the surrounding rock develops fully during the extraction of equipment. It is easy to break, rotate, and collapse the roof and crush the supports, and such events are likely to occur, as shown in Figure 1 [12]. For example, the roofs and supports in the 42107 panel of the Liangshuijing Coal Mine and the 1202 panel of the Fengjiata Coal Mine were damaged during the extraction of equipment. Mining cracks can directly reach the surface, and air, water, and sediment can enter the recovery roadway through cracks, which seriously affects the extraction of equipment. Therefore, the key to realizing safe and efficient production in mines is to study the stability control of the rock surrounding longwall recovery roadways [13].

The extraction technologies for longwall faces include shearer-driven roadway technology and predriven roadway technology. The technology of predriven roadways has obvious shortcomings, such as relatively large work quantities, high maintenance costs, and a high likelihood of roof collapse when crossing the predriven roadway [14]. At 


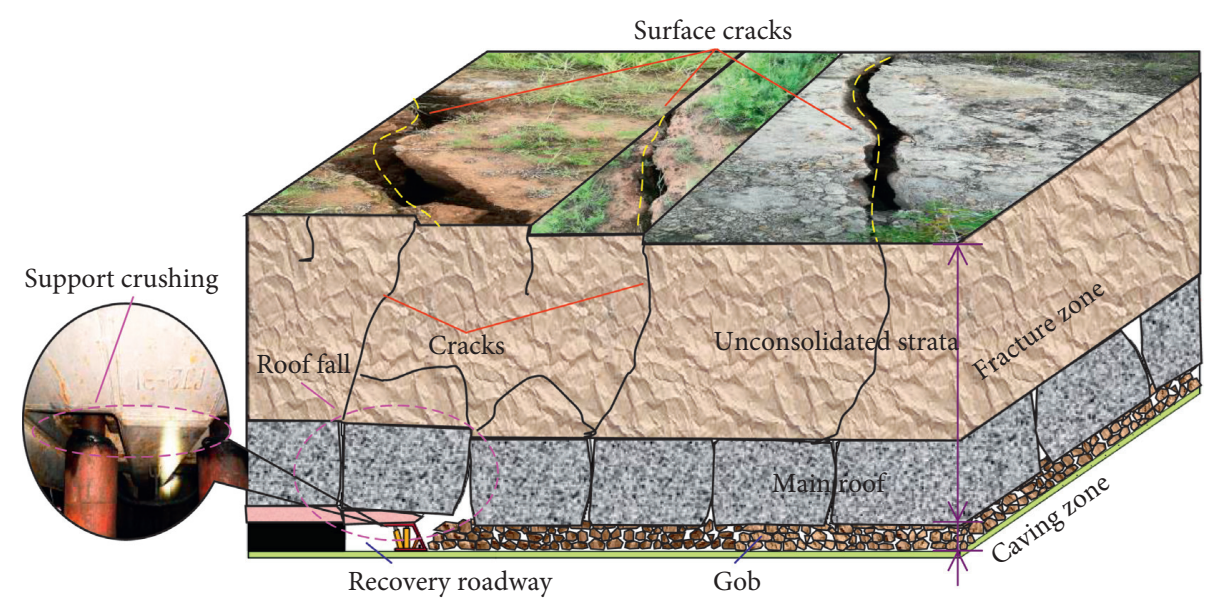

FIGURE 1: Roof and support damage during the extraction of equipment.

present, this technology is mainly used in mines with simple geological conditions such as the Shendong mining area. Most mines in China still apply shearer-driven roadway technology. The stability control of rock surrounding recovery roadways in shallow seams has been studied deeply at home and abroad. Numerous scholars have systematically studied support design for recovery roadways and the relationship between the support system, strata movement, and ground subsidence [14-16]. Some researchers have also proposed controlling the stability of rock surrounding recovery roadways by determining the applicability of an adapting roadway, evaluating potential accidents, and optimizing the locations of mesh installation [17, 18]. Other scholars have also studied the influence of mining-induced stress, the breaking locations of main roofs, the buried depth of the working face, the nature of rock strata, and mining heights on the stability of rock surrounding recovery roadways [19, 20]. However, the above research is mainly aimed at the stability control of rock surrounding predriven longwall recovery roadways in shallow seams. Few studies have focused on the stability control of rock surrounding shearer-driven longwall recovery roadways.

The key stratum structures of overlying strata in shallow seams can be divided into four types, as shown in Figure 2 [21]. There are significant differences in the breaking and migration laws of different key stratum structures. The overburden load of the recovery roadway is supported by the "coal wall-supporting structure-hydraulic support-gangue in gob" structure. Optimizing the bolting parameters of the recovery roadway can improve the supporting efficiency and reduce the development time of the plastic zone in the surrounding rock. Support with a reasonable working resistance can effectively protect the recovery roadway when the roof is unstable. Therefore, the bolting parameters of the recovery roadway and the reasonable working resistance of the support should be studied to realize the stability control of the surrounding rock.

This paper mainly studies the stability of the surrounding rock in shearer-driven recovery roadways. First, pressurerelief technology and its applicable conditions are introduced. Pressure-relief technology is an effective means of releasing the accumulated rock pressure in the roof before the extraction of equipment. Subsequently, mechanical models of roof instability are established for different key stratum structures. The formulas for calculating the reasonable working resistances of supports under different roof conditions are deduced theoretically. The Liangshuijing Coal Mine and Fengjiata Coal Mine are taken as research objects. According to the actual geological conditions of each working face, the reasonable working resistance of the support and the reasonable width of the recovery roadway are calculated. Based on the above results, a numerical simulation method is used to verify the surrounding rock control effect of the improved support design for the recovery roadway. The research results are in line with the field practice, which realizes the safe and rapid extraction of the supports.

\section{Pressure-Relief Technology}

In the mid-1990s, the "Key Strata Theory" of strata control was put forward [22]. This theory provides in-depth information about the progressive caving behavior of strata and its impacts on longwall operations. According to this theory, the stratum that controls the movement of all or part of the overburden is defined as the key stratum (KS); that is, when the KS breaks, all or part of the overburden above the KS will subside simultaneously. To be more specific, the former is defined as the primary key stratum (PKS), whereas the latter is defined as a subordinate key stratum (SKS). There may be several subordinate key strata in the overburden of the stope, but the PKS is unique and located above all the subordinate key strata. Generally, the SKS closest to the stope in the overburden is called SKS1, and the other subordinate key strata are called SKS2, SKS3, etc. from bottom to top until reaching the PKS. The rock strata with synchronous subsidence and deformation with each SKS are named weak stratum 1 (WS1), weak stratum 2 (WS2), etc., and the strata controlled by the PKS are called load strata. The stable state of SKS1 directly determines whether periodic weighting occurs in the stope. Therefore, SKS1 should be kept as stable as possible during the extraction of 


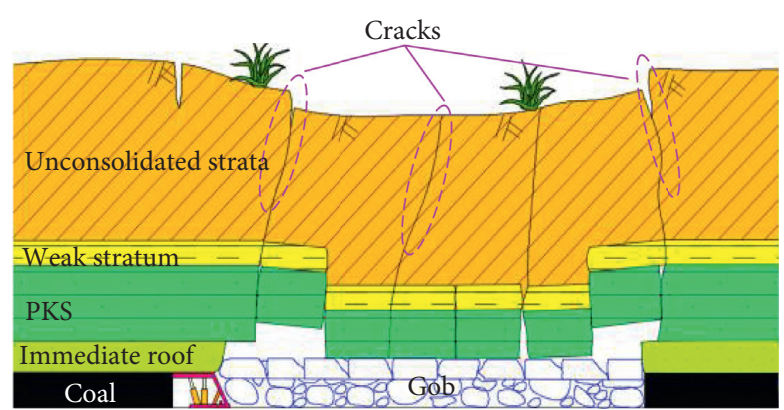

(a)

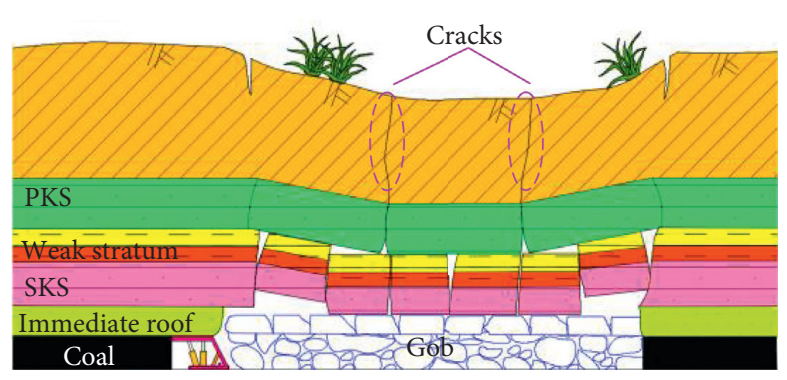

(c)

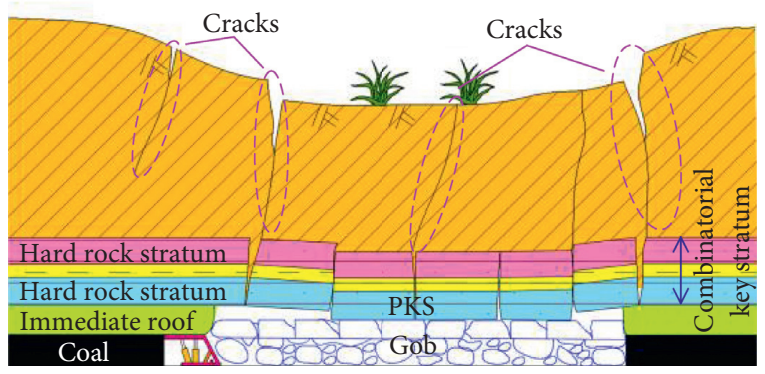

(b)

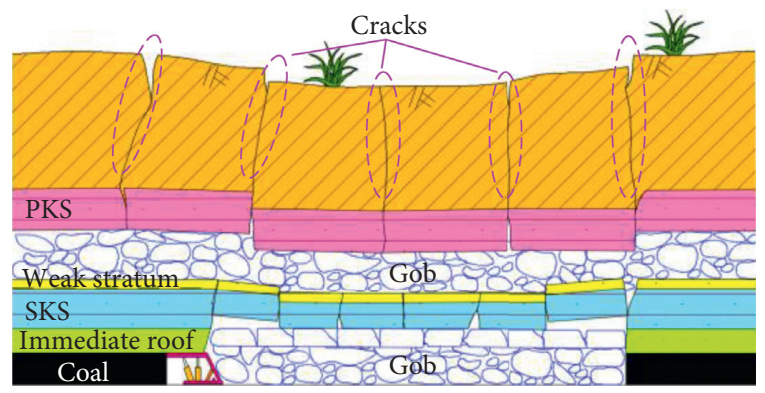

(d)

FIgURE 2: Types of key stratum structures in shallow seams: (a) thick and hard single-key stratum structure; (b) single-key stratum structure of a compound group; (c) multikey strata structure; (d) single-key stratum structure of an over-seam extracted group.

equipment. In general, the recovery roadway must be arranged according to the preset terminal line to maximize the exploitation of coal resources. If the law of weighting is not considered, periodic weighting may be necessary during the extraction of equipment, as shown in Figures 3(a)-3(c). Pressure-relief technology stops the advancement of the working face (usually 10 hours) before laying out the recovery roadway, which promotes the occurrence of periodic weighting according to fracture development. The working face continues to advance after periodic weighting. After the working face passes the weighting area, the recovery roadway can be arranged. The width of the weighting area is usually 2 to 3 times that of the regular circulation footage according to the statistical results of monitoring data of the rock pressure in Yushenfu Mining Area [16]. At this time, SKS1 can be ensured to be in as stable state as possible during the extraction of equipment, as shown in Figure 3(d).

Pressure-relief technology has certain applications. The technology should be applied reasonably according to roof conditions and the law of periodic weighting. For example, periodic weighting will not occur even if mining stops for a long time when the hanging length of SKS1 is less than 0.6 times the breaking interval or if there is a thick and hard roof above the working face. According to practical experience at Halagou Coal Mine and Xinhe Coal Mine, deep-hole presplitting blasting technology can be used to cut off the hanging roof $[23,24]$.

\section{Determining the Reasonable Working Resistance of the Support}

The shearer cuts the coal wall to arrange the recovery roadway after the rock pressure accumulated in the roof is released. Formula (1) is the basis for evaluating the stability of SKS1 above the recovery roadway. If the working resistance of the support is low, then roof and support damage may occur due to the instability of SKS1:

$$
l_{1}=d_{1}+d_{2}+d_{3} \geq k L_{1} \text {, }
$$

where $l_{1}$ is the hanging length of SKS1 $(\mathrm{m}) ; d_{1}$ is the width of the recovery roadway $(\mathrm{m}) ; d_{2}$ is the length of the hydraulic support $(\mathrm{m}) ; d_{3}$ is the reserve safe distance, which is generally 3 times the regular circulation footage according to engineering experience $(\mathrm{m}) ; L_{1}$ is the periodic weighting interval of SKS1 (m); and $k$ is the safety factor that ranges from 0.4 to 0.6. In this paper, the default value of $k$ is 0.6 .

Similarly, when the key stratum other than SKS1 in the overburden of the stope with a multikey strata structure is considered in formula (2), this stratum may break during the extraction of equipment. It is generally believed that SKS1 will break synchronously after the upper key stratum (UKS) is broken. Therefore, the stability of the UKS should be considered before the layout of the recovery roadway in the multikey strata structure stope:

$$
l_{m}=d_{1}+d_{2}+d_{3}+d_{4} \geq k L_{m}
$$

where $l_{m}$ is the hanging length of the UKS $(\mathrm{m}) ; d_{4}$ is the horizontal distance from the latest-breaking position of the UKS to the latest-breaking position of SKS1 (m); and $L_{m}$ is the periodic weighting interval of the UKS $(\mathrm{m})$.

It is known that when the hanging length of the key stratum in the overburden meets the requirements of formulae (1) or (2), this stratum breaks easily during the extraction of equipment. Therefore, it should be ensured that the support can provide enough support resistance to 


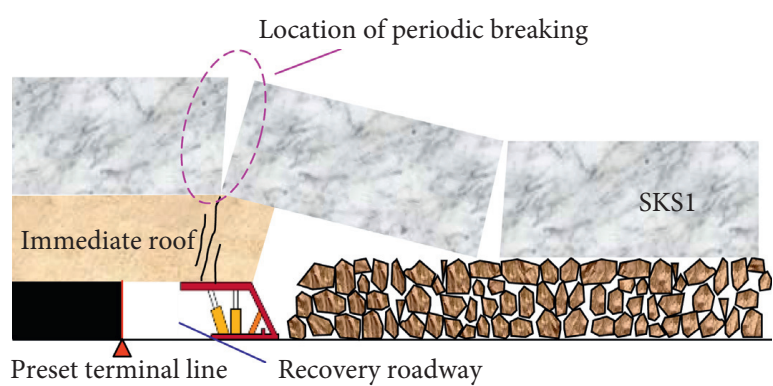

(a)

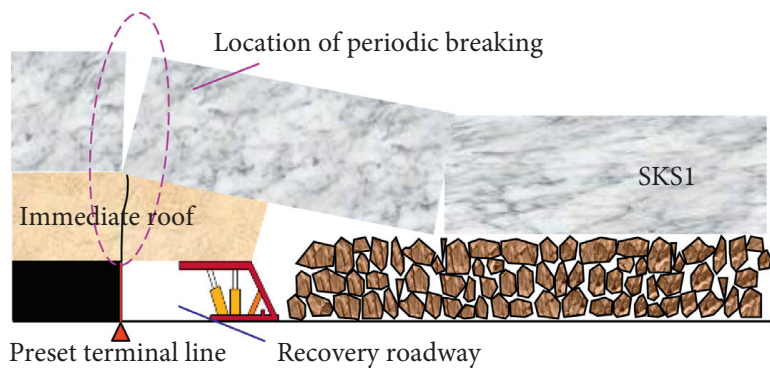

(c)

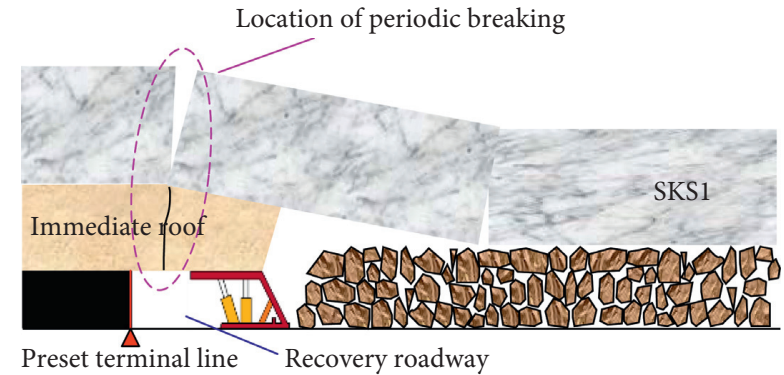

(b)

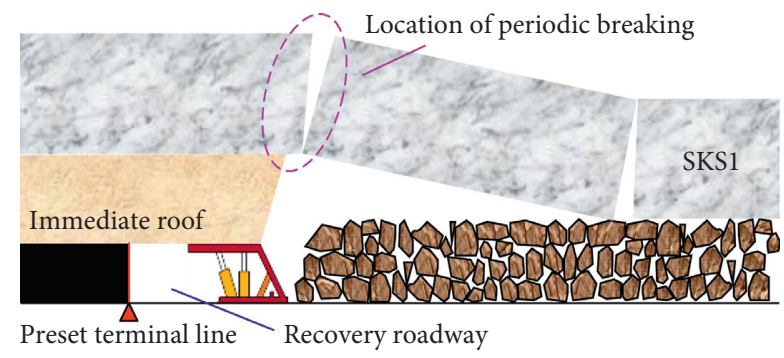

(d)

FIgURE 3: The position of periodic weighting during the extraction of equipment: (a) above the support; (b) above the recovery roadway; (c) along the coal wall; (d) above the gob.

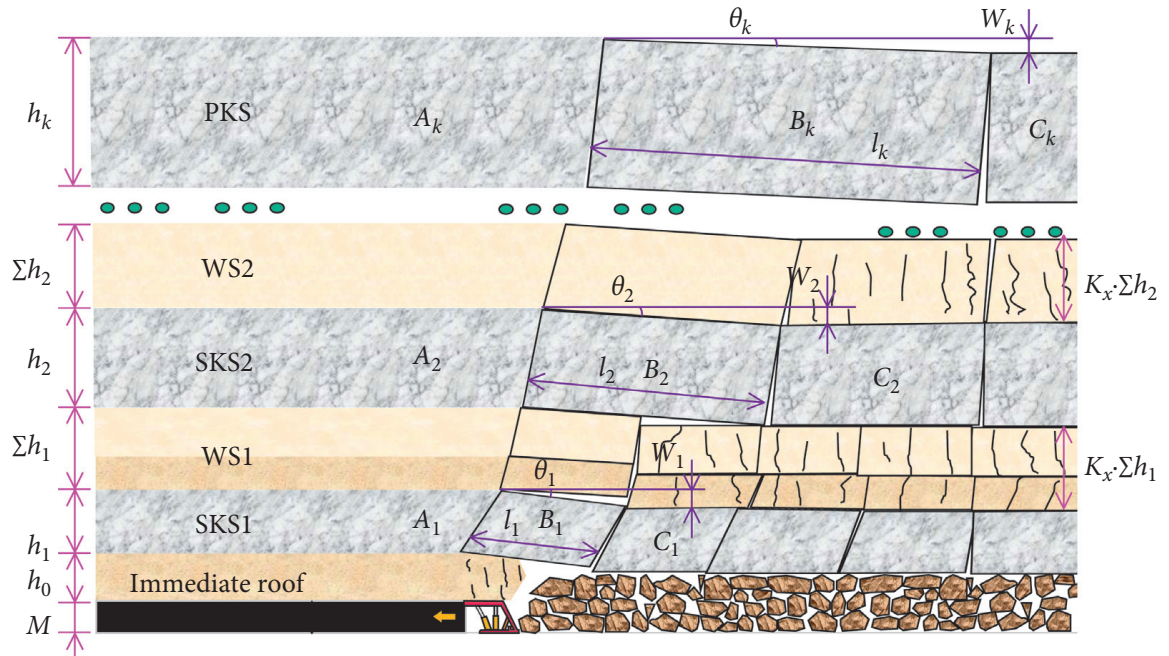

FIGURE 4: Roof model of a stope with a multikey stratum structure.

control the bench convergence of the roof. Generally, theoretical calculations are used to determine the reasonable working resistance of the support. The method calculates the support load by establishing the cantilever beam, voussoir beam, and other mechanical models of the broken blocks of key strata based on the Key Strata Theory. It can be seen that the premise of applying the theoretical calculation method is to first distinguish the breaking forms of key strata and the articulated forms of broken blocks.

3.1. The Breaking Forms of the Key Strata and the Articulated Forms of Broken Blocks. The breaking forms of key strata can be roughly divided into two types: cantilever beam and articulated beam. The difference between the two breaking forms is whether the absolute rotation of the broken block exceeds the maximum rotation of the articulated structure [25-27]. The breaking form of the UKS is influenced by the breaking form of the lower key stratum (LKS), as well as the thickness and bulking factor of the weak stratum between the two key strata. Because the breaking interval of the UKS is relatively large and the rotation space is limited, it must break in the form of an articulated beam when the LKS breaks in the form of an articulated beam. By combination with the above analysis, the discriminative approach of the structural form of the block after the key stratum is broken is obtained. (1) First, 
the breaking form of each key stratum is determined based on SKS1. (2) It is known that there are two kinds of instability forms of voussoir beam structures, namely, sliding instability and rotation instability [25]. The voussoir beam structure is stable only when the sliding instability and rotation instability do not occur simultaneously. According to the "Sliding-Rotation (S-R)" stability theory of the voussoir beam structure, the specific articulated form (voussoir beam, unstable voussoir beam, or step beam) of a broken block is determined, as illustrated by the roof model shown in Figure 4, where $M$ is the mining height $(\mathrm{m}), h_{0}$ is the thickness of the immediate roof $(\mathrm{m}), h_{1}-h_{k}$ is the thickness from SKS1 to PKS (m), $\sum h_{1}-\sum h_{k-1}$ is the thickness of the weak stratum controlled by each SKS (m), $l_{1}-l_{k}$ is the breaking interval from SKS1 to PKS (m), $\theta_{1}-\theta_{k}$ is the rotation angle of the broken block from SKS1 to PKS $\left({ }^{\circ}\right)$, and $W_{1}-W_{k}$ is the absolute rotation of the broken block from SKS1 to PKS (m).

The maximum rotation of the broken block of SKS1, which can form an articulated structure, is $\Delta_{1 \max }$. According to the mechanical model of deformation and the instability of the voussoir beam structure, $\Delta_{1 \max }$ can be determined by formula (3) [25-29]:

$$
\Delta_{1 \max }=h_{1}-\sqrt{\frac{2 q_{1} L_{1}^{2}}{\sigma_{1 \mathrm{c}}}},
$$

where $q_{1}$ is the load on SKS1 (MPa) and $\sigma_{1 \mathrm{c}}$ is the compressive strength of SKS1 (MPa).

The formula for calculating the absolute rotation $W_{1}$ is as follows:

$$
W_{1}=M-\left(K_{p}-1\right) h_{0},
$$

where $K_{p}$ is the bulking factor of the immediate roof and is generally taken as 1.3 .

By combining formulas (3) and (4), the criteria of SKS1 breaking in the forms of a cantilever beam and an articulated beam are obtained, respectively, and given by formulas (5) and (6):

$$
\begin{aligned}
& M-\left(K_{p}-1\right) h_{0}>h_{1}-\sqrt{\frac{2 q_{1} l_{1}^{2}}{\sigma_{1 \mathrm{c}}}}, \\
& M-\left(K_{p}-1\right) h_{0} \leq h_{1}-\sqrt{\frac{2 q_{1} l_{1}^{2}}{\sigma_{1 \mathrm{c}}}} .
\end{aligned}
$$

Field observations show that the bulking factor of WS1 is basically the same as $K_{p}$ when SKS1 is broken in the form of a cantilever beam. The bulking factor of WS1 is represented by $K_{p 0}$ when SKS1 is broken in the form of an articulated beam, and $K_{p 0}$ is generally taken as 1.05 . Therefore, the absolute rotation $W_{2}$ of the broken block of SKS2 is

$$
W_{2}=M-\left(K_{p}-1\right) h_{0}-\left(K_{x}-1\right) \sum h_{1},
$$

where the value of $K_{x}$ is $K_{p 0}$ or $K_{p}$, and the specific value is determined by the breaking form of SKS1. According to formula (6), the criterion indicating that the broken block of SKS2 can form an articulated beam is obtained:

$$
M-\left(K_{p}-1\right) h_{0}-\left(K_{x}-1\right) \sum h_{1} \leq h_{2}-\sqrt{\frac{2 q_{2} l_{2}^{2}}{\sigma_{2 c}}},
$$

where $q_{2}$ is the load on SKS2 (MPa) and $\sigma_{2 c}$ is the compressive strength of SKS2 (MPa). By analogy, the general discriminant formula describing the broken block of the key stratum forming an articulated beam is obtained:

$$
\begin{aligned}
W_{m}= & M-\left(K_{p}-1\right) h_{0}-\left(K_{x}-1\right) \sum h_{1}-\cdots-\left(K_{x}-1\right) \\
& \cdot \sum h_{m-1} \leq h_{m}-\sqrt{\frac{2 q_{m} l_{m}^{2}}{\sigma_{m c}}},
\end{aligned}
$$

where the value range of $m$ is from 1 to $k$.

The specific articulated from of the broken blocks can be further discriminated according to the S-R stability theory of a voussoir beam structure. Sliding instability and rotating instability will occur when the articulated beam structure cannot meet the requirements of formulas (10) and (11), respectively. In the two formulas, $\varphi$ is the internal friction angle of the broken block, $i_{m}$ is the lumpiness of the broken block (the ratio of height to length), and $\theta_{m}$ is determined by equation (12):

$$
\begin{gathered}
h_{m}+\sum h_{m} \leq \frac{\sigma_{m c}}{30 \gamma}\left(\tan \varphi+\frac{3}{4} \sin \theta_{m}\right)^{2}, \\
h_{m}+\sum h_{m} \leq \frac{0.15 \sigma_{m c}}{\gamma}\left(i_{m}^{2}-\frac{3}{2} i_{m} \sin \theta_{m}+\frac{1}{2} \sin ^{2} \theta_{m}\right), \\
\theta_{m}=\arcsin \left(\frac{W_{m}}{l_{m}}\right) .
\end{gathered}
$$

Research shows [25] that the lumpiness of the broken block of the key stratum in the overburden is large during the mining of shallow coal seams. The broken block will slide and lose stability behind the support when formula (13) is satisfied. At this time, the key stratum will break periodically in the form of a step beam. In summary, the discriminant conditions of the breaking form of key strata and the articulated form of broken blocks are obtained, as given by formula (14). 


$$
i_{m}>\frac{2 \cos \theta_{m}+3 \sin \theta_{m}}{4\left(1-\sin \theta_{m}\right)},
$$

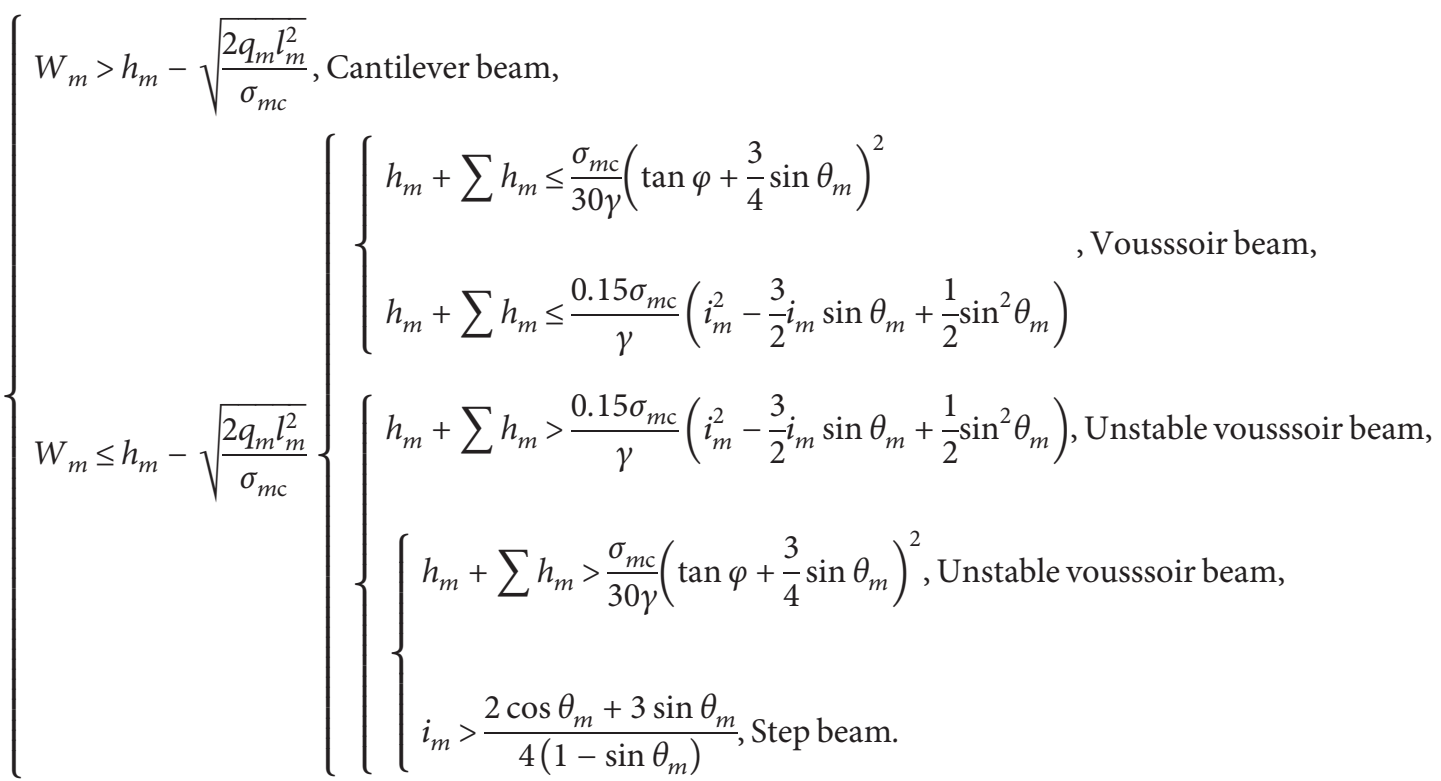

It is known that load transfer coefficients $C_{1}, C_{2}$ and $C_{3}$ of a cantilever beam (unstable voussoir beam), voussoir beam, and step beam are, respectively [25],

$$
C_{x}= \begin{cases}1, & x=1, \\ 2-\frac{l_{m} \tan (\varphi-\beta)}{2\left(h_{m}-W_{m}\right)}, & x=2, \\ 1-\tan \varphi \cdot \frac{\left(h_{m} / \sin \alpha\right) \cos \left(\alpha-\theta_{m}\right)+\left(l_{m} / 2\right) \cos \theta_{m}}{\left(h_{m} / \sin \alpha\right) \sin \left(\alpha-\theta_{m}\right)-W_{m}-0.5 a}, & x=3,\end{cases}
$$

where $\alpha$ is the breaking angle of the rock stratum $\left({ }^{\circ}\right) ; \beta$ is the angle between the fracture line and the vertical direction $\left({ }^{\circ}\right)$; and $a$ is the height of the extrusion contact surface at the end angle of the block (m), which is determined by formula (16).

$$
a=0.5\left(h_{m}-l_{m} \sin \theta_{m}\right) \text {. }
$$

Figure 5 is used as an example to discuss the calculation methods for the reasonable working resistance of a support based on different key stratum structures. Because the thick and hard single-key stratum structure is similar to the singlekey stratum structure of a compound group, this paper provides an explanation in a unified way. In Figure $5, \mathrm{H}_{z}$ is the thickness of the load strata $(\mathrm{m}), L_{k}$ is the hanging length of the immediate roof $(\mathrm{m}), R_{0}$ is the weight of the immediate roof above the recovery roadway and top beam $(\mathrm{kN}), R_{1}-R_{k}$ is the force acting on the substructure due to the broken block of each key stratum $(\mathrm{kN}), P_{1}-P_{k}$ is the sum of the deadweight of the broken block of each key stratum and the overlying load $(\mathrm{kN}), P_{l}$ is the load imposed on the lower structure by the load strata $(\mathrm{kN})$, and $P_{H}$ is the reasonable working resistance of the support $(\mathrm{kN})$.

\subsection{Reasonable Working Resistance of the Support in the Stope} with a Single-Key Stratum Structure. A single-key stratum structure means that there is only one key stratum in the roof of a shallow seam, which is the PKS. The instability mechanics model of a single-key stratum structure is shown in Figure 5(a).

The formula for calculating the support load $P_{z}$ is as follows:

$$
P_{z}=R_{0}+R_{1}
$$

$R_{0}$ and $R_{1}$ can be calculated by formulas (18) and (19), 


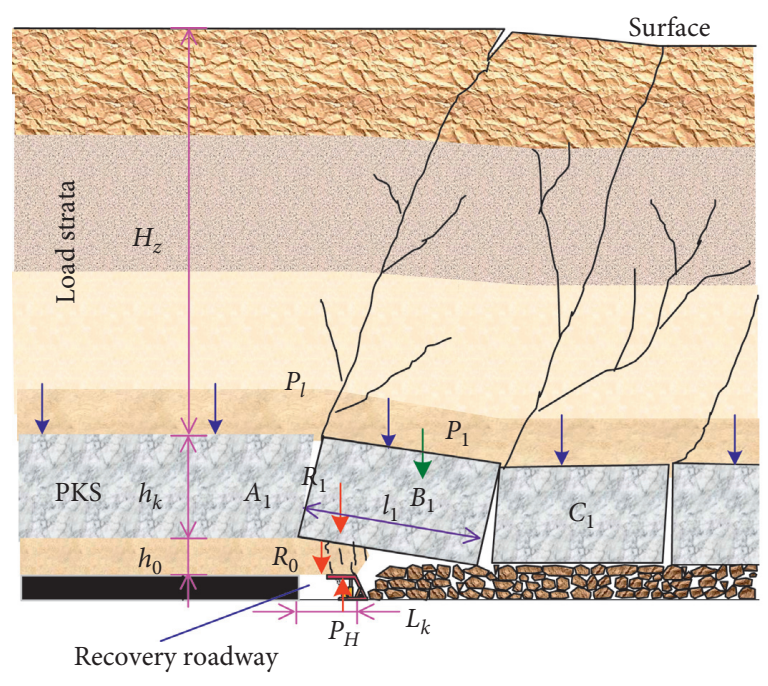

(a)

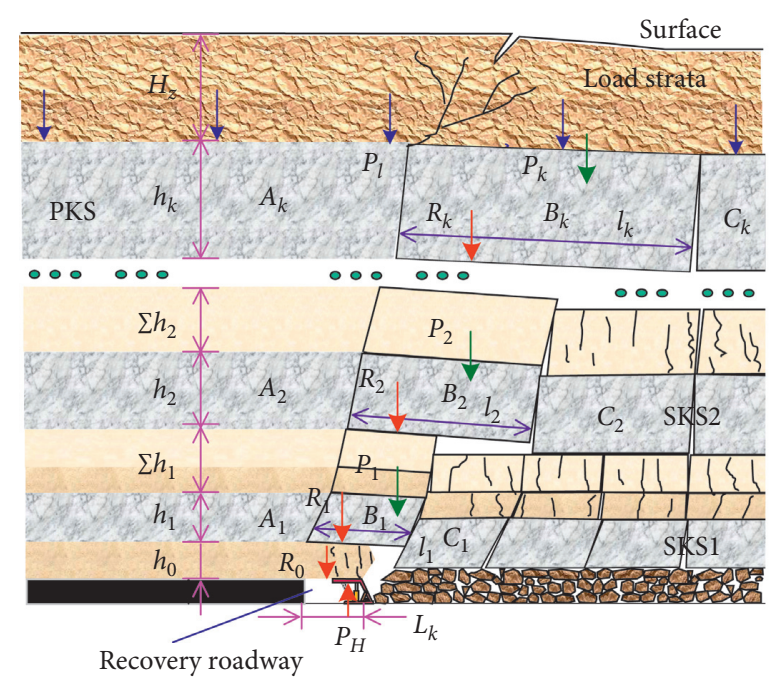

(b)

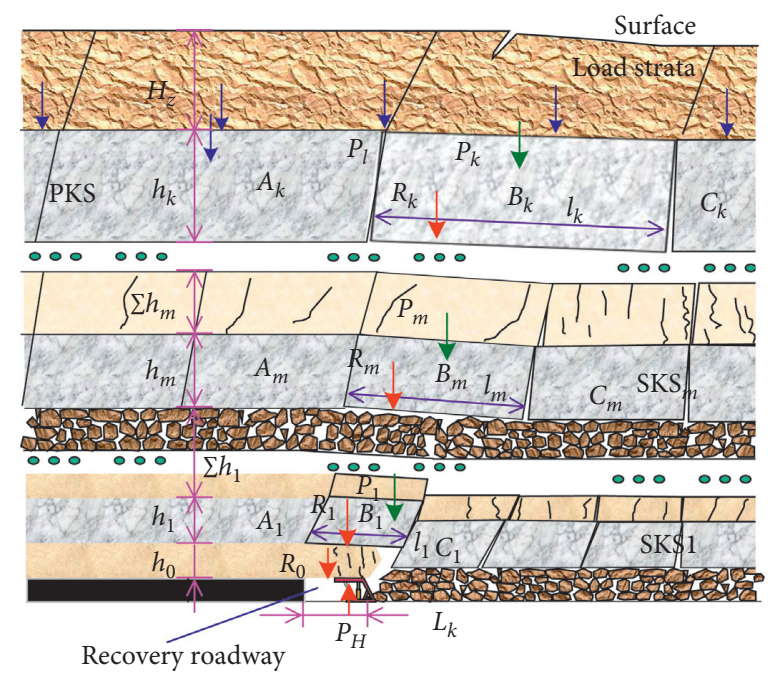

(c)

Figure 5: Mechanical models of the roof structure during periodic weighting: (a) instability mechanics model of a single-key stratum structure; (b) instability mechanics model of a multikey strata structure; (c) instability mechanics model of a single-key stratum structure of an over-seam extracted group.

respectively $[16,30,31]$ :

$$
\begin{aligned}
& R_{0}=\left(L_{k}+0.5 h_{0} \cot \alpha\right) b h_{0} \gamma, \\
& R_{1}=C_{x} \cdot P_{1}=C_{x} \cdot\left(l_{1} b h_{1} \gamma+P_{l}\right),
\end{aligned}
$$

where $b$ is the width of the hydraulic support and $\gamma$ is the average volume-weight of the stratum, which is generally taken as $25 \mathrm{kN} / \mathrm{m}^{3}$.

$P_{z}$ can be calculated by formula (20) $[25,30]$ :

$$
P_{l}=K_{G} l_{1} b H_{z} \gamma
$$

where $K_{G}$ is the load transfer coefficient of the load strata, and the calculation formula is

$$
K_{G}=\frac{0.8 l_{1}}{2 H_{z}\left(1-\sin \varphi_{1}\right) \tan \varphi_{1}},
$$

where $\varphi_{1}$ is the internal friction angle of the load strata $\left(^{\circ}\right)$. The calculation formula of the support resistance $P_{s}$ is obtained based on the above analysis:

$$
\begin{aligned}
P_{z}= & \left(L_{k}+0.5 h_{0} \cot \alpha\right) b h_{0} \gamma+C_{x} \\
& \cdot\left[l_{1} b h_{1} \gamma+\frac{0.8 l_{1}}{2 H_{z}\left(1-\sin \varphi_{1}\right) \tan \varphi_{1}} \cdot l_{1} b H_{z} \gamma\right] .
\end{aligned}
$$

Formula (22) is also used to calculate the support load of the stope with a single-key stratum structure of a compound group. However, in this case, $h_{1}$ is the total thickness of the single-key stratum of the compound group. The actual support efficiency of the support is 0.9 according to the research results of related literatures $[16,30,32]$. The reasonable working resistance $P_{H}$ of the support is determined by formula (23): 


$$
P_{H}=\frac{P_{z}}{0.9}
$$

3.3. Reasonable Working Resistance of the Support in a Stope with a Multikey Strata Structure. A multikey strata structure has multiple key strata above the coal seam. It is generally believed that when the distance between two key strata is less than $41 \mathrm{~m}$, there will be mutual influence [30]. An obvious nonuniform periodic weighting phenomenon occurs in a stope with a multikey strata structure. The stope will appear as weak periodic weighting when the LKS is broken and the UKS is stable. At this time, the strength of periodic weighting is relatively low because the UKS obstructs the transmission of the overburden load. The instability load acts on the LKS when the UKS is broken, which causes two key strata to break simultaneously. Strong periodic weighting will occur in the stope at this time [33]. Strong periodic weighting should be guaranteed to occur in the multikey strata before the recovery roadway is laid out. However, the key stratum in the overburden of a stope with a multikey strata structure may still break during the extraction of the equipment when the hanging length of the key stratum meets formula (1) or (2). The instability mechanics model of the multikey strata structure is shown in Figure 5(b). In this case, $R_{1}$ is calculated by formula (24) [34-36]:

$$
\begin{aligned}
R_{1} & =C_{x} \cdot P_{1}=C_{x} \cdot\left[l_{1} b \gamma\left(h_{1}+\sum h_{1}\right)+R_{2}\right] \\
& =C_{x} \cdot\left[l_{1} b \gamma\left(h_{1}+\sum h_{1}\right)+C_{x} \cdot\left(\cdots+C_{x} \cdot P_{k}\right)\right] .
\end{aligned}
$$

Therefore, the calculation formula of the support resistance $P_{z}$ is

$$
\begin{aligned}
P_{z}= & \left(L_{k}+0.5 h_{0} \cot \alpha\right) b h_{0} \gamma+C_{x} \\
& \cdot\left[l_{1} b \gamma\left(h_{1}+\sum h_{1}\right)+C_{x} \cdot\left(\cdots+C_{x} \cdot P_{k}\right)\right] .
\end{aligned}
$$

3.4. Reasonable Working Resistance of the Support in a Stope with a Single-Key Stratum Structure under the Gob. The key stratum in the overburden is broken after the upper seam is mined. Therefore, SKS1 will act as the PKS, as shown in Figure 5(c). However, there is still a connection of the horizontal forces between the broken blocks, and an articulated structure can still be formed due to the effect of mining the lower coal seam. It is difficult to accurately determine the migration law of the broken blocks in the overburden of the upper coal seam during the mining of the lower coal seam. Therefore, the support resistance $P_{z}$ should be considered in the case of SKS1 synchronous breaking caused by the instability and rotation of the broken blocks. Additionally, the compacted rock mass in the caving zone of the upper coal seam can be regarded as a weak stratum. The calculation formula of the support resistance $P_{z}$ is the same as formula (25).

\section{Engineering Background}

The Liangshuijing Coal Mine and Fengjiata Coal Mine are both located in the Yushenfu Mining Area. The geographical locations of the two mines are shown in Figure 6. Accidents due to roof and support damage have occurred in both mines during equipment extraction.

4.1. \#3-1 Coal Seam in the Liangshuijing Coal Mine. The approved production capacity of the Liangshuijing Coal Mine is $8 \mathrm{Mt} / \mathrm{a}$. The \#3-1 coal seam is the main mining seam in this mine. The occurrence characteristics of the coal strata are shown in Figure 7. The \#3-1 coal seam and its roof and floor were drilled and sampled, and then the samples were processed into standard test pieces in the laboratory. A mechanical testing and simulation (MTS) universal testing machine is applied to test the mechanical parameters of the coal strata [37, 38]; see Table 1 for details. The overlying strata are determined to be a single-key stratum structure according to the discrimination conditions of the key stratum $[39,40]$. Fine sandstone with a thickness of $9 \mathrm{~m}$ is the PKS, according to the definition of the PKS. The regular circulation footage is $0.8 \mathrm{~m}$, and the gob roof is treated by a caving method. The working face is equipped with ZY8000/ 17.5/35-type supports.

Field practice shows that when the width of the recovery roadway is half the length of the support, the supports can be successfully extracted. Therefore, the reasonable width of the recovery roadway is determined according to the length of the support, the regular circulation footage, and the safe distance of a certain width. It is known that the length and width of the ZY8000/17.5/35-type support are $6 \mathrm{~m}$ and $1.66 \mathrm{~m}$, respectively. The reasonable width of the recovery roadway was set to $3.2 \mathrm{~m}$ by considering that the regular circulation footage is $0.8 \mathrm{~m}$. According to the measured rock pressure data in the \#3-1 coal seam, the working resistance curve of the support was drawn as shown in Figure 8. A total of 13 periodic weightings are monitored. The average interval of the periodic weighting is approximately $16.7 \mathrm{~m}$. By substituting the values of each parameter into formula (1), we can obtain $l_{1}=11.6 \mathrm{~m}$. Thus, SKS1 is easy to break during the extraction of equipment.

By referencing the related literature $[16,25,27]$, the following are assumed: $\varphi=39.5^{\circ}, \alpha=90^{\circ}$, and $\beta=0^{\circ} . L_{k}$ is the sum of the width of the recovery roadway and the length of the top beam. It is known that the length of the top beam is $4.1 \mathrm{~m}$, and $L_{k}=7.3 \mathrm{~m}$ is determined after calculation. The compressive strength of fine sandstone, $\sigma_{1 \mathrm{c}}=50.5 \mathrm{MPa}$, is derived from laboratory test data. According to the mining conditions of \#3-1 coal seam and the previous statement, the following are determined: $l_{1}=11.6 \mathrm{~m}, b=1.66 \mathrm{~m}, \varphi_{1}=33^{\circ}$, and $M=3 \mathrm{~m}$. After calculation by formulas (3) and (4), $\Delta_{1 \max }=5.76 \mathrm{~m}$ and $W_{1}=1.8 \mathrm{~m}$ are obtained. According to formula (14), the broken block of SKS1 will form a stepbeam structure during the extraction of equipment. Therefore, formula (26) is used to calculate the support load $P_{z}$. The result shows that $P_{z}=5220 \mathrm{kN}$; that is, $P_{H}=5800 \mathrm{kN}$. 


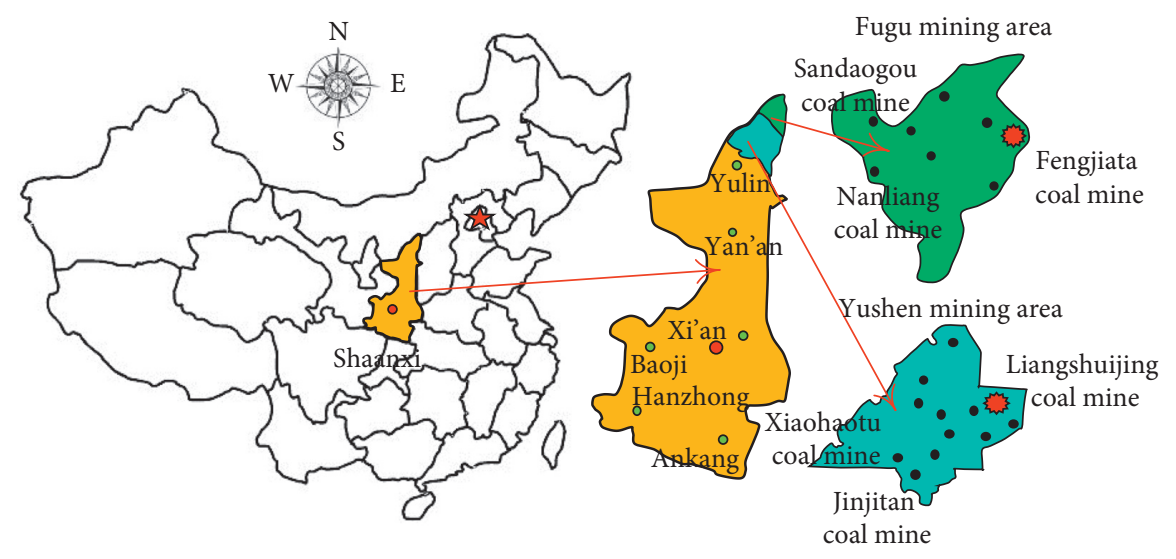

FIgURE 6: Geographical locations of the two mines.

\begin{tabular}{|l|c|c|c|c|c|}
\hline No. & $\begin{array}{c}\text { THK } \\
(\mathrm{m})\end{array}$ & $\begin{array}{c}\text { Depth } \\
(\mathrm{m})\end{array}$ & Lithology & KS location \\
\hline 1 & 2.82 & 2.82 & Aeolian sand & \\
\hline 2 & 3.23 & 6.05 & Fine sand & \\
\hline 3 & 17.95 & 24.00 & Loess & \\
\hline 4 & 78.30 & 102.30 & Clay & \\
\hline 5 & 7.46 & 109.76 & Siltstone & \\
\hline 6 & 4.36 & 114.12 & Mudstone & \\
\hline 7 & 9.00 & 123.12 & Fine sandstone & PKS \\
\hline 8 & 4.00 & 127.12 & Siltstone & \\
\hline 9 & 3.03 & 130.15 & \#3-1 coal seam & \\
\hline 10 & 1.10 & 131.25 & Siltstone & \\
\hline 11 & 4.81 & 136.06 & Fine sandstone & \\
\hline
\end{tabular}

FIGURE 7: Bore hole columnar section of the coal strata in the Liangshuijing coal mine.

TABLE 1: Physical and mechanical parameters of the coal strata in the Liangshuijing coal mine.

\begin{tabular}{|c|c|c|c|c|c|c|}
\hline $\begin{array}{l}\text { Rock } \\
\text { formations }\end{array}$ & $\begin{array}{c}\text { Bulk modulus } \\
(\mathrm{GPa})\end{array}$ & $\begin{array}{c}\text { Shear } \\
\text { modulus (GPa) }\end{array}$ & $\begin{array}{c}\text { Density } \\
\left(\mathrm{kg} \cdot \mathrm{m}^{-3}\right)\end{array}$ & $\begin{array}{l}\text { Friction } \\
\text { angle }\left({ }^{\circ}\right)\end{array}$ & $\begin{array}{c}\text { Cohesion } \\
(\mathrm{MPa})\end{array}$ & Tensile strength $(\mathrm{MPa})$ \\
\hline Aeolian & 0.0125 & 0.0071 & 1760 & 23 & 0.019 & \\
\hline Fine sand & 0.0242 & 0.0136 & 1810 & 20 & 0.003 & \\
\hline Loess & 0.0383 & 0.0177 & 1860 & 27 & 0.0016 & \\
\hline Clay & 0.28 & 0.093 & 1960 & 25 & 0.85 & \\
\hline Siltstone & 4.3 & 3.36 & 2730 & 32.9 & 4.1 & 3.2 \\
\hline Mudstone & 2.86 & 1.4 & 2540 & 39 & 2.8 & 2.48 \\
\hline Fine sandstone & 16.04 & 12.02 & 2800 & 43 & 9.2 & 8.5 \\
\hline Siltstone & 5 & 3.8 & 2630 & 35 & 3.8 & 2.75 \\
\hline \#3-1 coal seam & 2.8 & 1.2 & 1420 & 27 & 0.6 & 0.4 \\
\hline Siltstone & 6.25 & 3.57 & 2570 & 31.4 & 9.2 & 8.5 \\
\hline Fine sandstone & 21.01 & 13.52 & 2873 & 42 & 3.2 & 1.29 \\
\hline
\end{tabular}

This result shows that the working resistance of the selected supports in the \#3-1 coal seam is low. Therefore, the selected supports in the \#3-1 coal seam can meet the requirements of the roof support during the extraction of equipment.
4.2. \#2 Coal Seam in the Fengjiata Coal Mine. The Fengjiata Coal Mine is located in the eastern part of the Fugu Mining Area, and its approved production capacity is $6 \mathrm{Mt} / \mathrm{a}$. The \#2 and \#4 coal seams are mined at the same time in this mine. The occurrence characteristics of the coal strata are shown in 


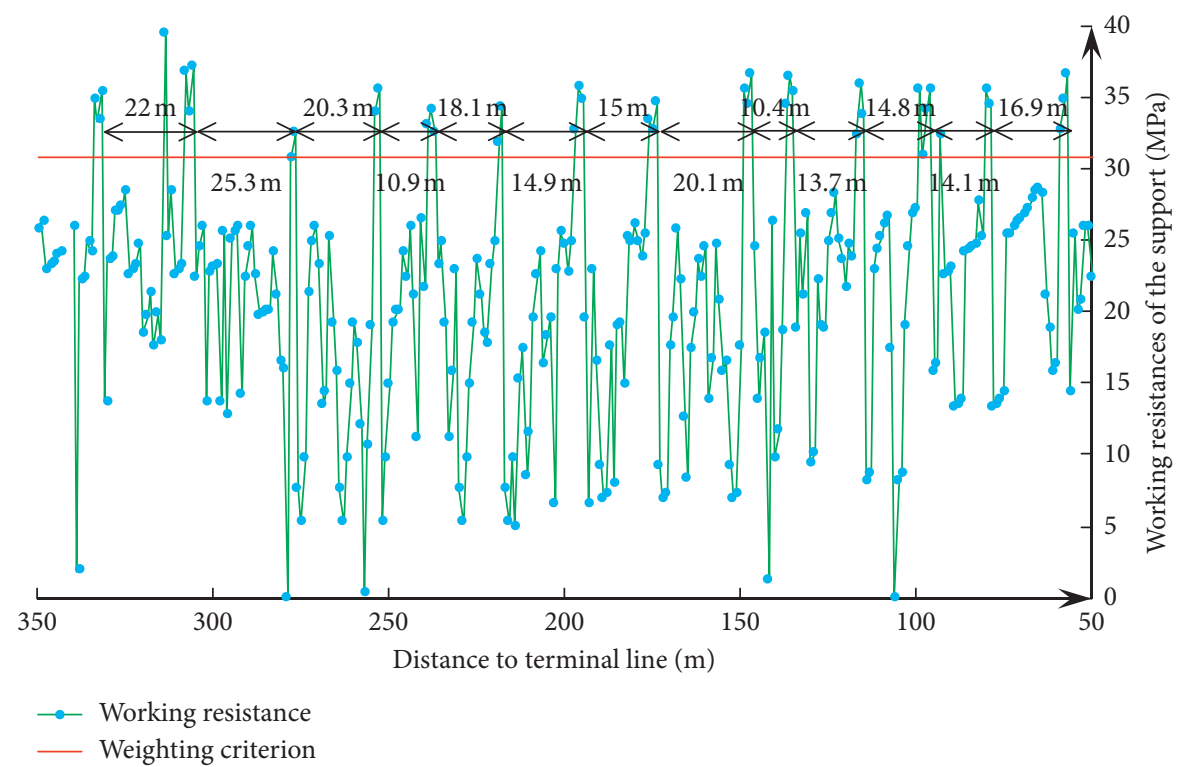

FIGURE 8: Working resistance curve of the support during the mining of the \#3-1 coal seam.

Figure 9. The mechanical parameters of the coal strata are determined by mechanical tests, as shown in Table 2. A multikey strata structure exists in the roof of the \#2 coal seam. According to the definitions of PKS and SKS, a medium coarse sandstone stratum with a thickness of $7.5 \mathrm{~m}$ is the SKS closest to the stope, and a medium sandstone stratum with a thickness of $10.82 \mathrm{~m}$ is the PKS. The regular circulation footage of the working face is $0.8 \mathrm{~m}$. The working face is equipped with ZY8500/20/42-type supports.

The length and width of the ZY8500/20/42-type support are $6.6 \mathrm{~m}$ and $1.75 \mathrm{~m}$, respectively. The reasonable width of the recovery roadway is set to $4 \mathrm{~m}$ by considering that the regular circulation footage is $0.8 \mathrm{~m}$. Figure 10 plots the periodic weighting law observed during the last mining period of the \#2 coal seam. The figure shows that a nonuniform periodic weighting phenomenon occurred in the working face. The strength of the strong-period weighting is approximately 1.22 times that of the weak-period weighting. The average interval of the strong-period weighting is approximately $36.2 \mathrm{~m}$ and that of the weak-period weighting is approximately $18 \mathrm{~m}$. By substituting the values of each parameter into formula (1), we obtain $l_{1}=13 \mathrm{~m}$. Thus, SKS2 breaks easily during the extraction of equipment. When pressure-relief technology is applied in advance to release the accumulated rock pressure in the PKS, according to formula (2), the PKS will be in a steady state during the extraction of equipment.

By combining working-face mining conditions and fieldmonitoring data, the following are determined: $l_{2}=13 \mathrm{~m}$, $b=1.75 \mathrm{~m}$, and $M=3 \mathrm{~m}$. It is known that the length of the top beam is $4.5 \mathrm{~m}$, and $L_{k}=8.5 \mathrm{~m}$ is determined after calculation. The compressive strength of medium coarse sandstone, $\sigma_{2 \mathrm{c}}=68.4 \mathrm{MPa}$, is derived from laboratory test data. The values of $\alpha, \beta, \varphi$, and $\varphi_{1}$ are the same as those provided above. After calculation by formulas (3) and (4), $\Delta_{2 \max }=5.3 \mathrm{~m}$ and $W_{2}=2.8 \mathrm{~m}$ are obtained. According to formula (14), the broken block of SKS2 will form a voussoir beam structure during the extraction of equipment. Therefore, formula (27) is used to calculate the support load $P_{z}$. The result shows that $P_{z}=8247 \mathrm{kN}$. This result shows that the selected support in the \#2 coal seam can basically meet the requirements of the roof support.

$$
P_{s}=\left(L_{k}+0.5 h_{0} \cot \alpha\right) b h_{0} \gamma+\left[2-\frac{l_{2} \tan (\varphi-\beta)}{2\left(h_{2}-W_{2}\right)}\right] \cdot\left(L_{2} b \gamma h_{2}+L_{2} b \gamma \sum h_{2}\right) \text {. }
$$

4.3. \#4 Coal Seam in the Fengjiata Coal Mine. The average distance between the \#2 coal seam and the \#4 coal seam is only $12.4 \mathrm{~m}$. SKS1 will act as the PKS during the mining of the \#4 coal seam. The working face is also equipped with ZY8500/20/42-type supports. The reasonable width of the recovery roadway that meets the extraction requirements is $4 \mathrm{~m}$, which is consistent with that of the \#2 coal seam. Figure 11 shows the periodic weighting law observed during the last mining period of the \#4 coal seam. The strength of the periodic weighting varies greatly. Low-strength periodic weighting is caused by the breakage of the SKS. Highstrength periodic weighting occurs because the rotational instability of the broken block of the PKS causes SKS1 to break. The average interval of periodic weighting is approximately $10.7 \mathrm{~m}$. Therefore, it can be determined that SKS1 must break during the extraction of equipment.

The reasonable working resistance of the support is considered in the case of synchronous instability of each key 


\begin{tabular}{|l|l|c|c|c|}
\hline No. & $\begin{array}{c}\text { THK } \\
(\mathrm{m})\end{array}$ & $\begin{array}{c}\text { Depth } \\
(\mathrm{m})\end{array}$ & Lithology & KS location \\
\hline 7 & 6.85 & 62.45 & Sandy mudstone & \\
\hline 9 & 10.82 & 73.27 & Medium grain sandstone & PKS \\
\hline 10 & 5.71 & 77.98 & Sandy mudstone & \\
\hline 11 & 5.60 & 88.91 & Coarse sandstone & \\
\hline 12 & 4.85 & 93.76 & Sandy mudstone & \\
\hline 13 & 5.00 & 98.76 & Medium grain sandstone & \\
\hline 14 & 4.61 & 103.37 & Coarse sandstone & \\
\hline 15 & 7.50 & 110.87 & Medium coarse sandstone & SKS2 \\
\hline 16 & 1.52 & 112.39 & Sandy mudstone & \\
\hline 17 & 3.30 & 115.69 & \#2 coal seam & \\
\hline 18 & 2.13 & 117.82 & Sandy mudstone & \\
\hline 20 & 2.05 & 119.87 & \#3 coal seam & \\
\hline 21 & 11.7 & 131.57 & Pelitic siltstone & SKS1 \\
\hline 21 & 2.11 & 133.68 & Coal seam & \\
\hline 23 & 3.30 & 139.12 & \#4 coal seam & \\
\hline
\end{tabular}

FIgURE 9: Bore hole columnar section of the coal strata in the Fengjiata coal mine.

TABle 2: Physical and mechanical parameters of the coal strata in the Fengjiata coal mine.

\begin{tabular}{|c|c|c|c|c|c|c|}
\hline Rock formations & Bulk modulus (GPa) & Shear modulus (GPa) & $\begin{array}{c}\text { Density } \\
\left(\mathrm{kg} \cdot \mathrm{m}^{-3}\right)\end{array}$ & Friction angle $\left({ }^{\circ}\right)$ & $\begin{array}{c}\text { Cohesion } \\
(\mathrm{MPa})\end{array}$ & $\begin{array}{c}\text { Tensile strength } \\
(\mathrm{MPa})\end{array}$ \\
\hline Loess & 0.040 & 0.019 & 1880 & 27 & 0.0018 & \\
\hline Subclay & 0.15 & 0.054 & 1840 & 23 & 0.52 & \\
\hline Clay & 0.28 & 0.093 & 1960 & 25 & 0.85 & \\
\hline Sandy mudstone & 2.56 & 2.36 & 2510 & 40 & 2.45 & 2.01 \\
\hline Pelitic siltstone & 2.2 & 1.05 & 2650 & 42 & 1.88 & 1.77 \\
\hline Coarse sandstone & 15.29 & 8.31 & 2890 & 30.6 & 12.4 & 13.1 \\
\hline Sandy mudstone & 4.9 & 3.2 & 2520 & 35 & 1.18 & 1.8 \\
\hline Fine sandstone & 6.25 & 3.57 & 2570 & 31.4 & 9.2 & 8.5 \\
\hline Pelitic siltstone & 4.2 & 2.65 & 2490 & 39 & 3.2 & 1.29 \\
\hline Medium coarse sandstone & 18.7 & 12 & 2550 & 37.5 & 11.5 & 7.8 \\
\hline Sandy mudstone & 7.5 & 4.2 & 2500 & 29 & 4.5 & 2.5 \\
\hline$\# 2$ coal seam & 5 & 2.3 & 1380 & 28 & 1 & 0.5 \\
\hline Sandy mudstone & 4.3 & 2.8 & 2545 & 37 & 3.2 & 2.25 \\
\hline \#3 coal seam & 5.6 & 2.3 & 1390 & 28 & 1 & 0.5 \\
\hline Siltstone & 10.83 & 8.13 & 2460 & 38 & 3.75 & 1.84 \\
\hline Pelitic siltstone & 4.3 & 3.36 & 2730 & 32.9 & 6 & 2.5 \\
\hline \#4 coal seam & 2.5 & 1.72 & 1420 & 29.5 & 2.11 & 2.6 \\
\hline Pelitic siltstone & 6.27 & 5.19 & 2665 & 44.5 & 11.5 & 7.8 \\
\hline
\end{tabular}

stratum. It is known that $L_{k}=8.5 \mathrm{~m}, L_{1}=10.7 \mathrm{~m}, L_{2}=18 \mathrm{~m}$, $L_{3}=36.2 \mathrm{~m}, b=1.75 \mathrm{~m}, M=3.3 \mathrm{~m}$, and $\sigma_{2 c}=68.4 \mathrm{MPa}$. The results of mechanical tests show that $\sigma_{1 \mathrm{c}}=49.5 \mathrm{MPa}$ and $\sigma_{3 \mathrm{c}}=53.5 \mathrm{MPa}$. According to formula (14), the form of the key strata in the overburden is step beam-voussoir beam- unstable voussoir beam. Therefore, formula (28) is used to calculate the support load $P_{z}$. The result shows that $P_{z}=9580 \mathrm{kN}$; that is, $P_{H}=10644 \mathrm{kN}$. This result shows that the yield load of the selected support in the \#4 coal seam is low. 


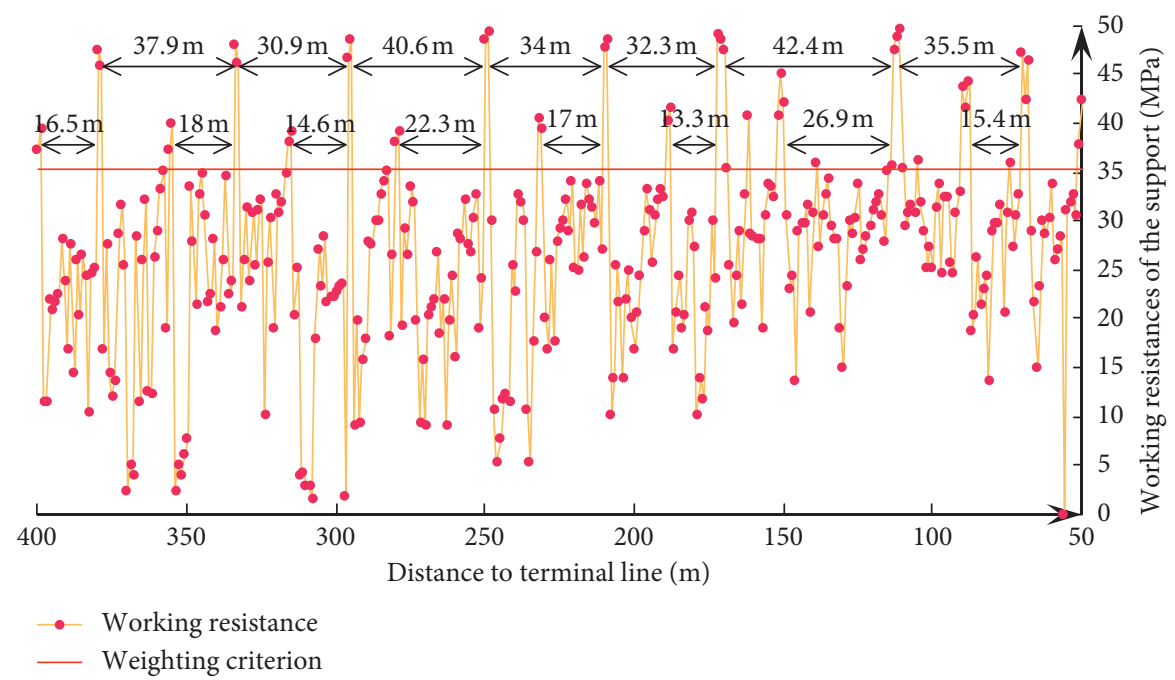

FIGURE 10: Working resistance curve of the support during the mining of the \#2 coal seam.

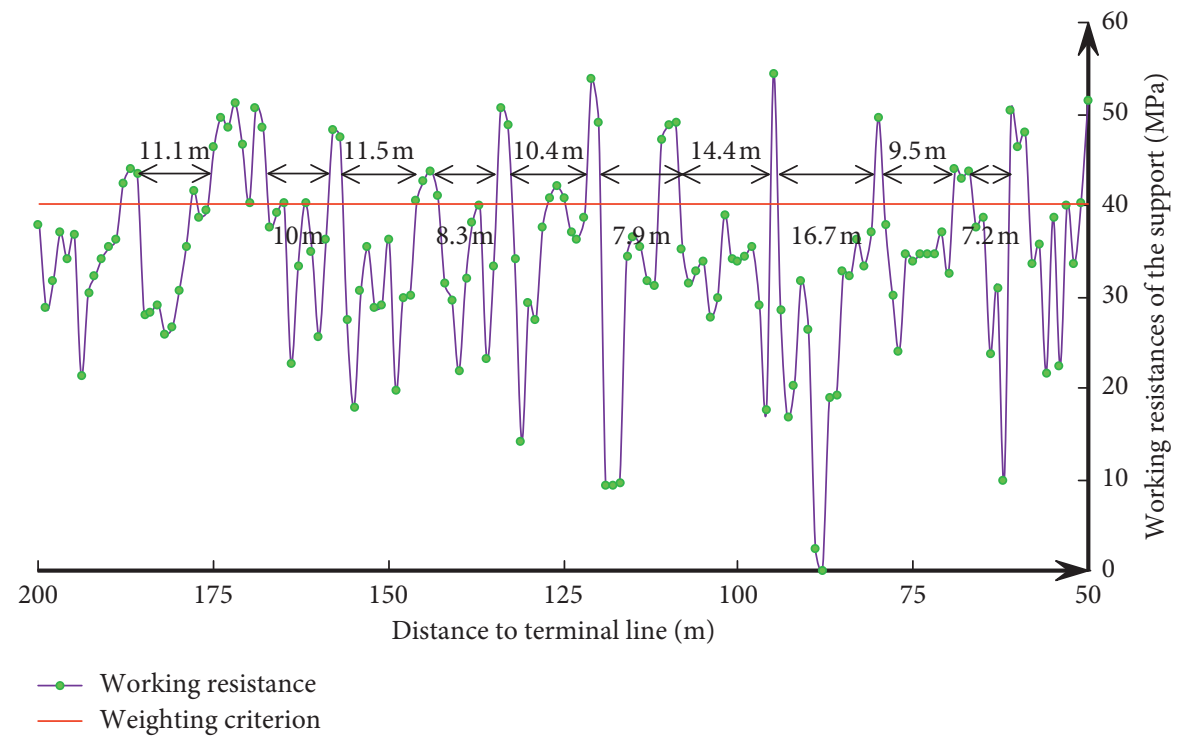

Figure 11: Working resistance curve of the support during the mining of the \#4 coal seam.

$$
\begin{aligned}
& P_{s}=\left(L_{k}+0.5 h_{0} \cot \alpha\right) b h_{0} \gamma+\left[1-\tan \varphi \cdot \frac{\left(h_{1} / \sin \alpha\right) \cos \left(\alpha-\theta_{1}\right)+\left(l_{1} / 2\right) \cos \theta_{1}}{\left(h_{1} / \sin \alpha\right) \sin \left(\alpha-\theta_{1}\right)-W_{1}-0.5 a}\right] . \\
& \quad\left\{L_{1} b \gamma\left(h_{1}+\sum h_{1}\right)+\left[2-\frac{L_{2} \tan (\varphi-\beta)}{2\left(h_{2}-W_{2}\right)}\right] \cdot\left(L_{2} b \gamma\left(h_{2}+\sum h_{2}\right)+L_{3} b \gamma h_{3}+\frac{0.8 L_{3}}{2 H_{z}\left(1-\sin \varphi_{1}\right) \tan \varphi_{1}} \cdot L_{3} b H_{z} \gamma\right)\right\} .
\end{aligned}
$$

\section{Numerical Simulation of the Recovery Roadway Support Design}

Based on the actual geological conditions of the Liangshuijing Coal Mine and Fengjiata Coal Mine, FLAC2D software is applied to establish numerical models to study the reasonable support parameters of the recovery roadway. The numerical model of the recovery roadway of Liangshuijing coal mine shown in Figure 12 was taken as an example to illustrate the modeling process. The MohrCoulomb constitutive model was applied to all models [41]. A uniform load was applied in the vertical direction to simulate the gravity of the overlying strata. We used the stress-relief method to investigate the in situ stress in the Liangshuijing Coal Mine. Field measurements showed that the vertical stress was $3.55 \mathrm{MPa}$; the minimum principal stress was parallel to the longwall face advancing direction, with a value of $1.81 \mathrm{MPa}$; and the maximum principal stress 


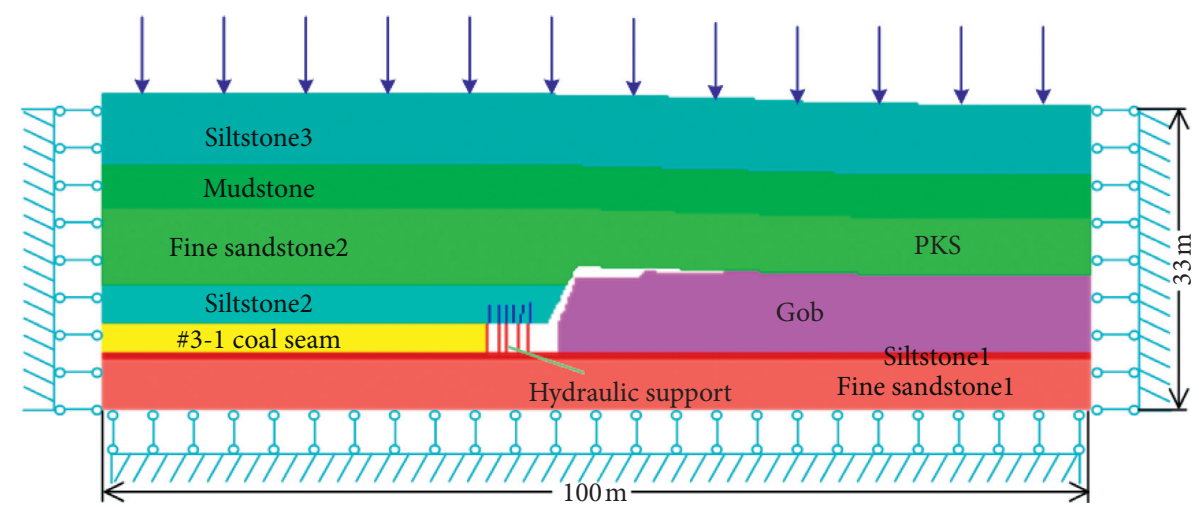

FIgURE 12: Numerical model of the recovery roadway in the Liangshuijing coal mine.

was $4.14 \mathrm{MPa}$. According to the test results of the in situ stress, the horizontal lateral pressure coefficient was determined to be 0.5 . The upper boundary was a free surface, the bottom boundary was restricted to move vertically, and the side boundaries around the model restricted horizontal movement [42]. The double-yield constitutive model of the compacted rock mass in the gob was established. The numerical simulation parameters of the compacted rock mass are shown in Table 3, according to the compaction theory in the gob [43-46].

5.1. Optimization of the Recovery Roadway Support Design in the \#3-1 Coal Seam. In the past, the Liangshuijing Coal Mine used an engineering analogy method to formulate the support design of recovery roadways. The support parameters are shown in Figure 13.

The steel beam is made of round steel with dimensions of $\Phi 16 \mathrm{~mm} \times 6,000 \mathrm{~mm}$. Each steel beam connects six rockbolts. JDPET200 $* 200 \mathrm{MS}$-type resin mesh was selected. The actual construction of the initial support design was time-consuming. Adequate development time was given for the plastic zone in the surrounding rock. The deformation of the rock surrounding the recovery roadway was large, which affected the normal operation of extraction. The actual supporting efficiency of the roof rockbolts near the gob was low and could not meet the requirements of rapid extraction. The initial support design was optimized based on the above problems, as shown in Figure 14. (1) Three wire ropes were laid instead of 3 rows of rockbolts near the gob. The diameter of the wire rope was $21.5 \mathrm{~mm}$, and the spacing was $800 \mathrm{~mm}$. (2) Adjacent rockbolts were replaced with anchor cables.

The numerical simulation method was applied to compare the surrounding rock control effects of the two support designs. Refer to Table 1 to determine the physical and mechanical parameters of each rock stratum in the model. The setting load of the support was set to $6400 \mathrm{kN}$, and the yield load was set to $8000 \mathrm{kN}$. The mechanical parameters of the rockbolts and cables in the model were obtained according to field test data and the data provided by the manufacturer; see Table 4 for details [47]. The anchoring force of the rockbolt was ensured to be greater than $105 \mathrm{kN}$. The pretightening force of the anchor cable was not less than $100 \mathrm{kN}$, and the anchoring force was not less than $150 \mathrm{kN}$. The grout properties were consistent with laboratory data obtained by performing pull-out tests on the rockbolts used in the physical model [36]. In this model, 10,000 time steps were calculated for each meter that the working face advanced to simulate the influence of mining on the overburden. After each rockbolt was installed, 1,000 time steps were calculated. After the recovery roadway support was completed, 100,000 time steps were run. The wire rope was not simulated in the model because it was used to fix the resin mesh.

Figure 15 shows the distribution of the plastic zone after the two support designs were simulated.

Figure 15 shows the following. (1) The lithology of the immediate roof was weak, and plastic failure occurred during the simulation support. Plastic failure also occurred in the PKS adjacent to the gob. (2) The plastic zone in the roof was divided into a shear failure zone, a plastic failure zone, and a tensile-failure zone. The development range of the plastic zone in each section was larger than that achieved with the improved support design because the initial support design ran more steps. (3) Because of the low support strength behind the support in the improved support design, the range of the tensile-failure zone was larger than that in the initial support design. (4) The deformation of the surrounding rock behind the support in the improved support design was larger than that in the initial support design because of the low tensile strength of the rock. However, this effect would not have a significant impact on the normal extraction of equipment.

The roof subsidence curves of each section for the two support designs are shown in Figure 16.

As shown in Figure 16, (1) the roof subsidence increased monotonically from the terminal line to the rear of the support; (2) the roof subsidence slowed near the rockbolt; and (3) the roof subsidence of each section in the initial support design was significantly larger than that in the improved support design. The results show that the surrounding rock control effect of the improved support design is better than that of the initial support design. 
TABLE 3: Numerical simulation parameters of the compacted rock mass in the gob.

\begin{tabular}{lccccc}
\hline Bulk modulus $(\mathrm{GPa})$ & Shear modulus $(\mathrm{GPa})$ & Density $\left(\mathrm{kg} \cdot \mathrm{m}^{-3}\right)$ & Friction angle $\left({ }^{\circ}\right)$ & Cohesion $(\mathrm{MPa})$ & Tensile strength $(\mathrm{MPa})$ \\
\hline 0.497 & 0.298 & 1800 & 5 & 0.001 & 0
\end{tabular}

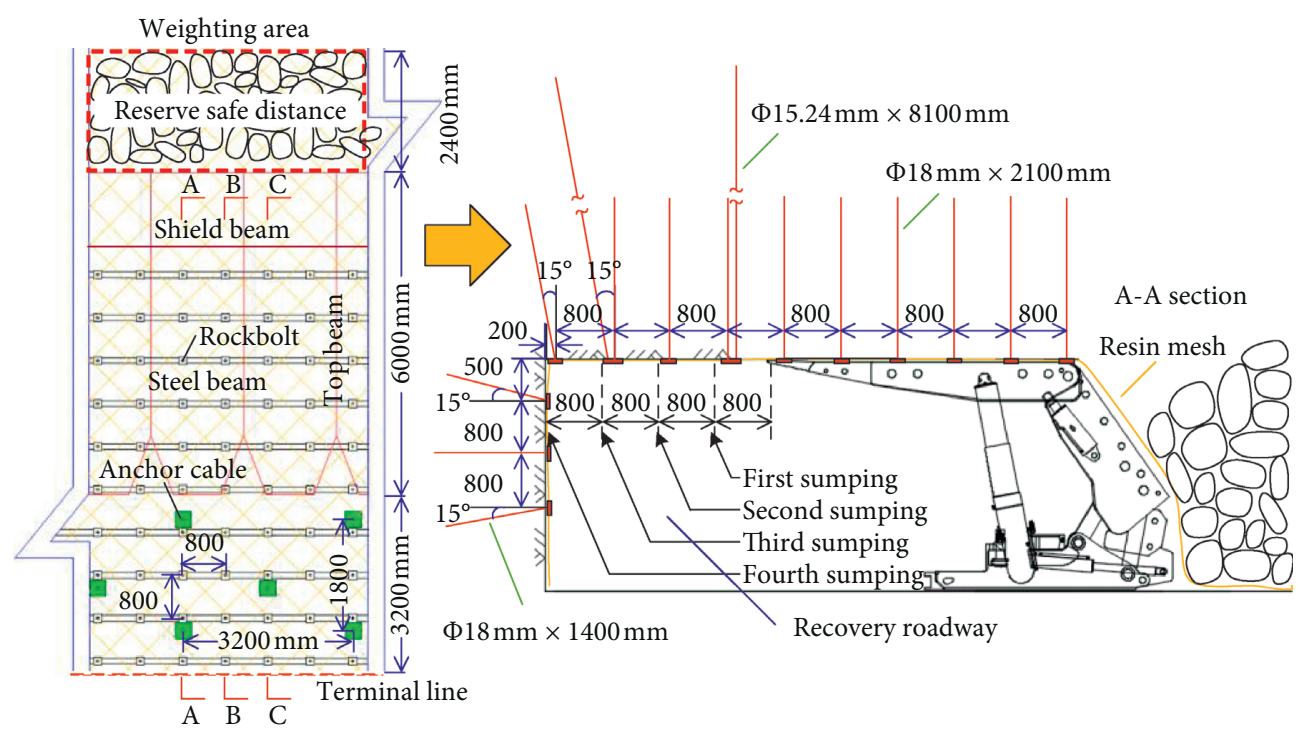

Figure 13: Initial support design of the recovery roadway in the \#3-1 coal seam.

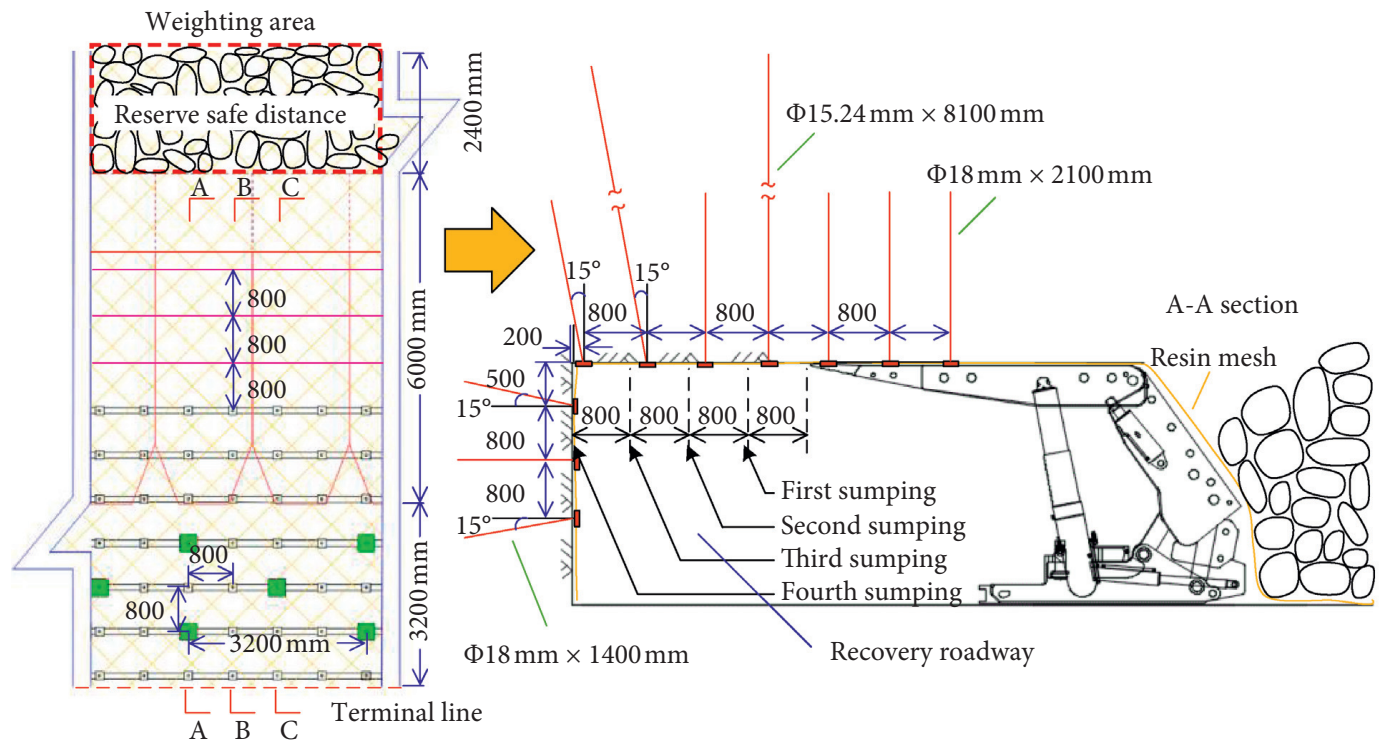

FIGURE 14: Improved support design of the recovery roadway in the \#3-1 coal seam.

TABLE 4: Mechanical parameters of the rockbolts and cables.

\begin{tabular}{lccccc}
\hline $\begin{array}{l}\text { Supporting } \\
\text { materials }\end{array}$ & $\begin{array}{c}\text { Elastic modulus } \\
(\mathrm{GPa})\end{array}$ & $\begin{array}{c}\text { Cross-sectional } \\
\text { area }\left(\mathrm{m}^{2}\right)\end{array}$ & $\begin{array}{c}\text { Tensile strength } \\
(\mathrm{MPa})\end{array}$ & $\begin{array}{c}\text { Stiffness of anchorage } \\
\text { agent }(\mathrm{GPa})\end{array}$ & $\begin{array}{c}\text { Cohesion of anchorage agent } \\
(\mathrm{mN} / \mathrm{m})\end{array}$ \\
\hline Rockbolts & 20 & 0.00025 & 250 & 5.35 & 0.42 \\
Flank rockbolts & 20 & 0.00025 & 200 & 5.35 & 0.42 \\
Cables & 20000 & 0.00018 & 1900 & 5.35 & 0.42 \\
\hline
\end{tabular}




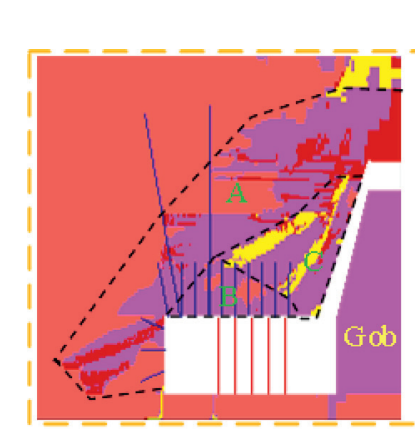

A-A section

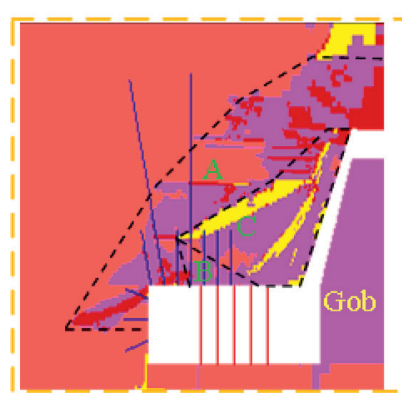

State

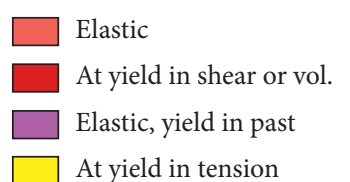

Initial support design

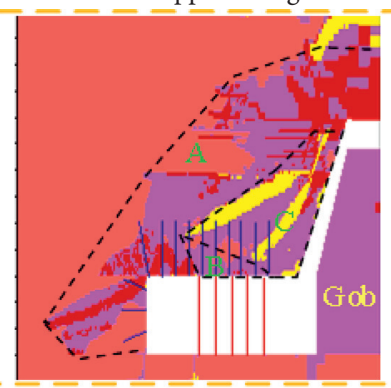

B-B section

Improved support design

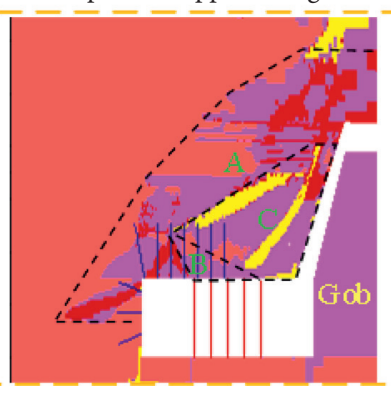

I.

I- $\overline{-} \overline{-}$ Plastic failure zone

I

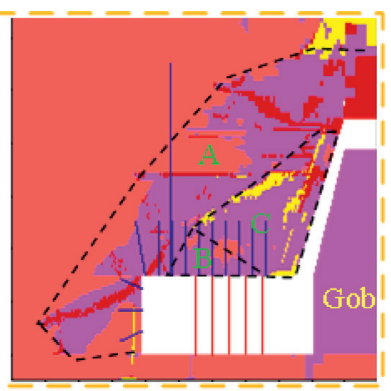

C-C section

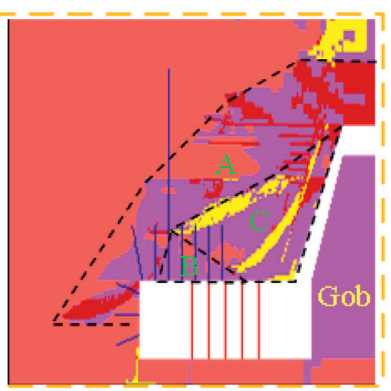

Cable plot

_ Rockbolt plot

_ Support plot

Figure 15: Plastic zone distribution of the two support designs.

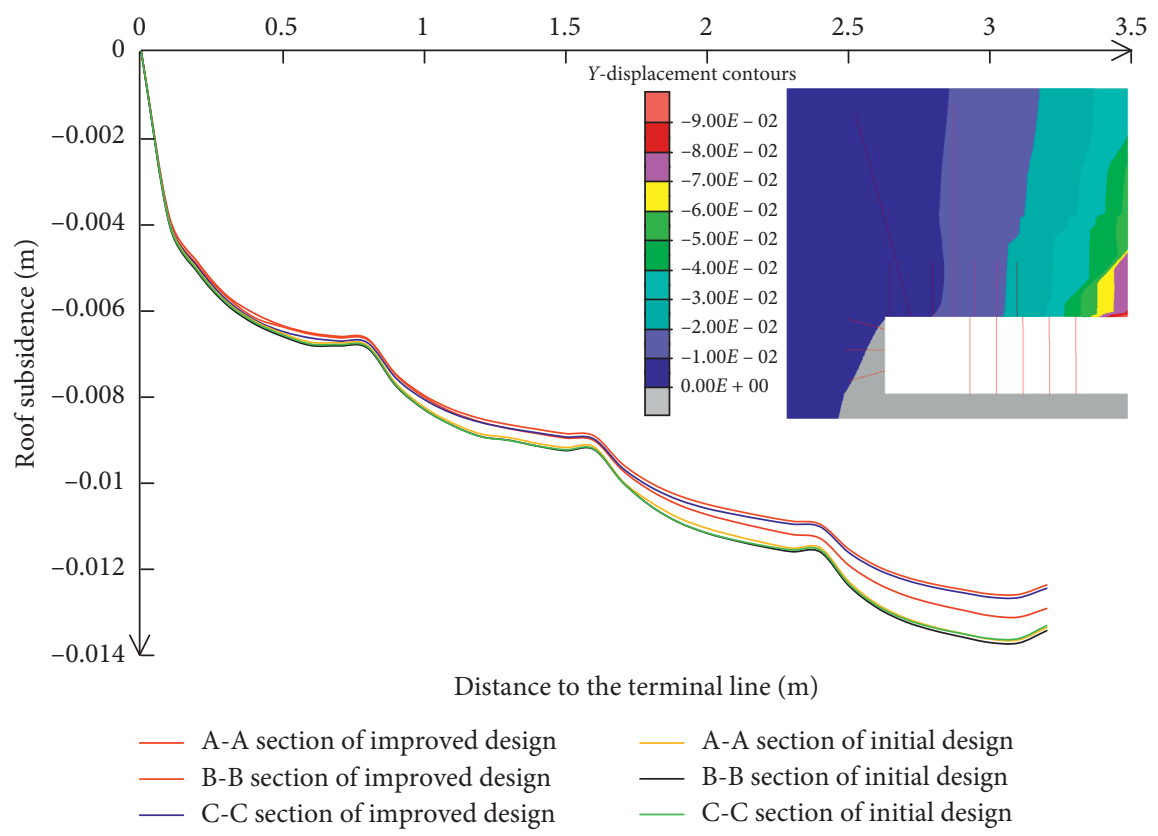

FIGURE 16: Roof subsidence curves of each section for the two support designs.

5.2. Optimization of the Recovery Roadway Support Design in the \#2 Coal Seam. The initial support design of the recovery roadway in the Fengjiata Coal Mine is shown in Figure 17.
The initial support design was improved, as shown in Figure 18, by considering the development of the plastic zone in the surrounding rock. Four wire ropes were laid 


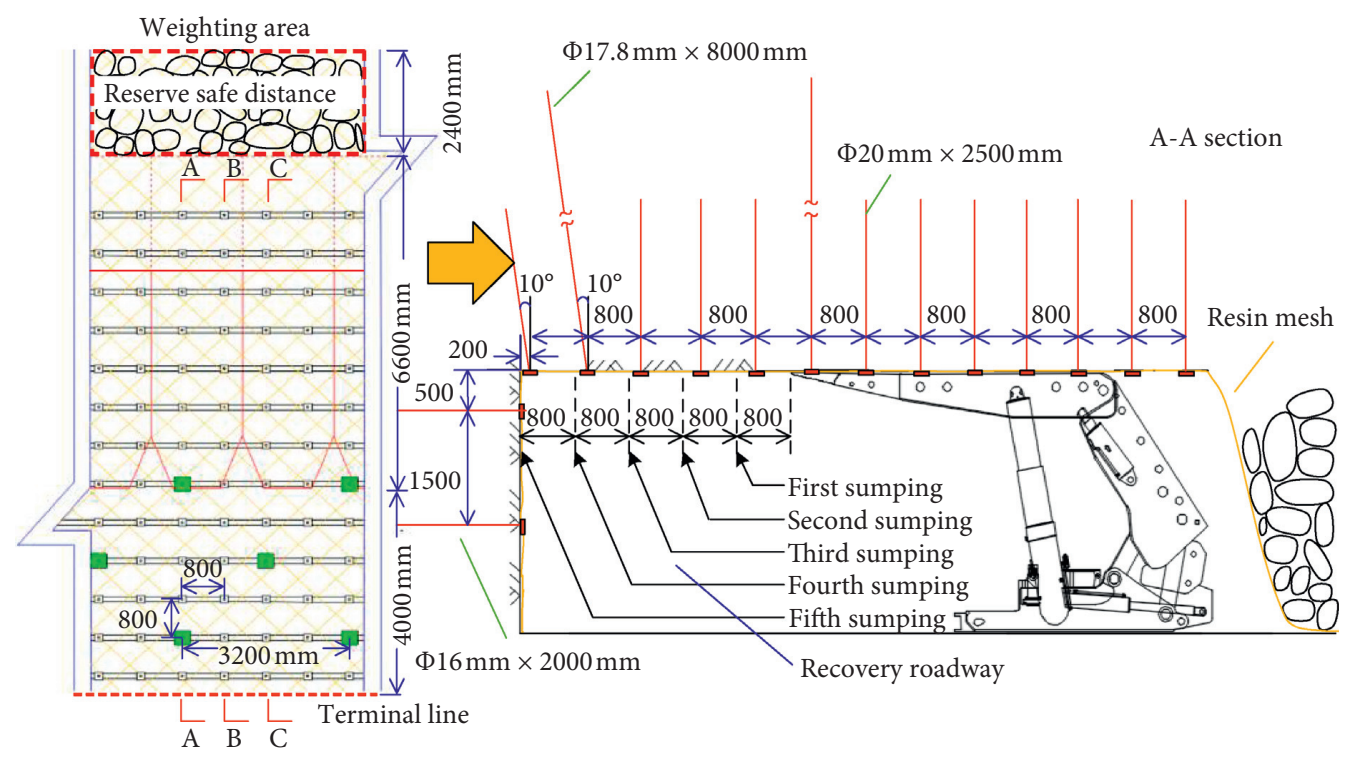

FIgURE 17: Initial support design of the recovery roadway in the Fengjiata coal mine.

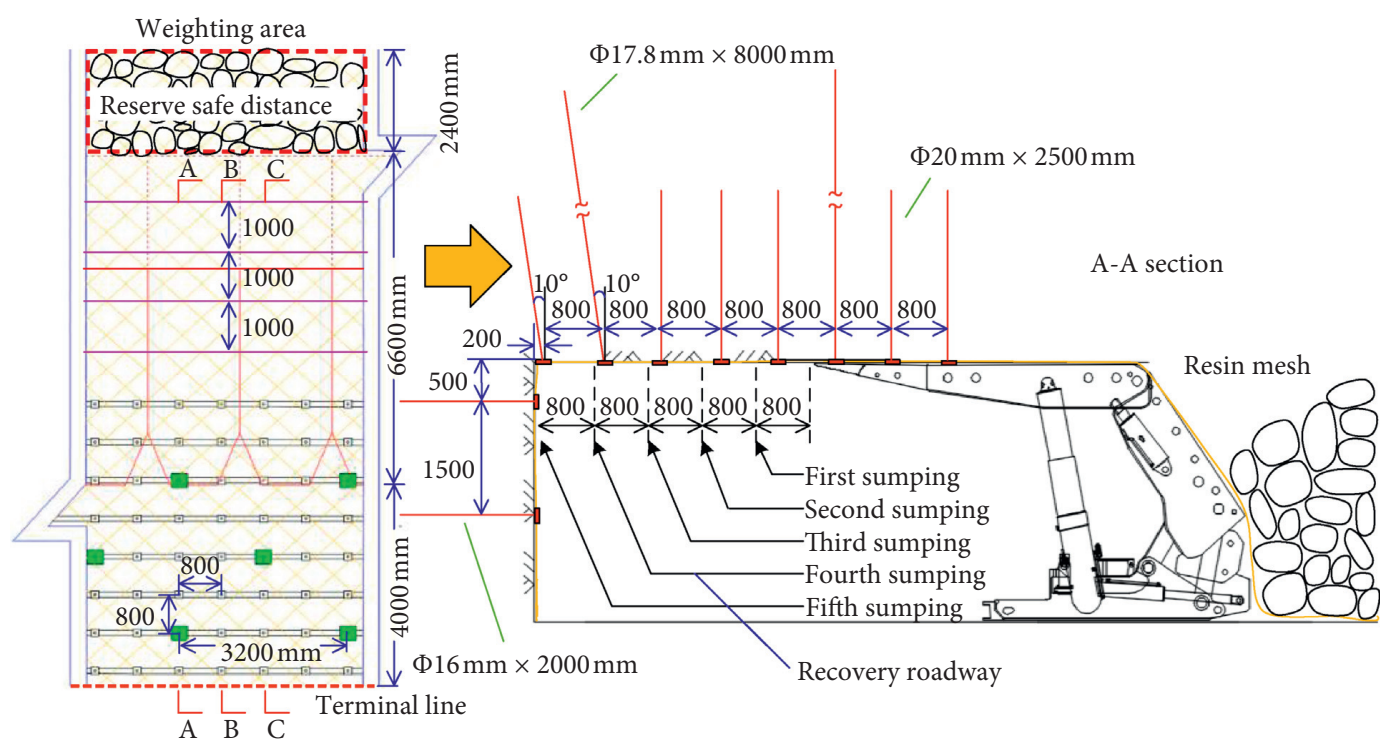

FIGURE 18: Improved support design of the recovery roadway in the Fengjiata coal mine.

instead of 5 rows of rockbolts near the gob. The diameter of the wire rope was $21.5 \mathrm{~mm}$, and the spacing was $1000 \mathrm{~mm}$.

The processes of excavation and the calculation of the model were consistent with those mentioned above. The setting load of the support was set at $6800 \mathrm{kN}$, and the yield load was set at $8500 \mathrm{kN}$ in the simulation of the two support designs. Figure 19 shows the distribution of the plastic zone after the two support designs were simulated.

Figure 19 shows the following: (1) the roof directly above the recovery roadway underwent integral plastic failure with the two support designs; (2) plastic failure occurred in SKS2 above the support; and (3) the development range of the plastic zone in the surrounding rock of the improved support design was smaller than that of the initial support design.
The roof subsidence curves of each section in the two support designs are shown in Figure 20.

The roof subsidence of the improved support design was significantly lower than that of the initial support design. Therefore, a decision was made to apply the improved support design in the recovery roadway of the \#2 coal seam.

5.3. Optimization of the Recovery Roadway Support Design in the \#4 Coal Seam. The initial support design and improved support design of the recovery roadway in the \#4 coal seam were consistent with those in the \#2 coal seam. The yield load of the support was $8500 \mathrm{kN}$ in the simulation of the initial support design, and the yield load of the support was $9600 \mathrm{kN}$ in the simulation of the 


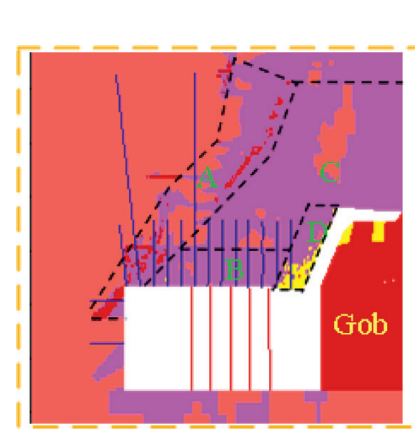

A-A section

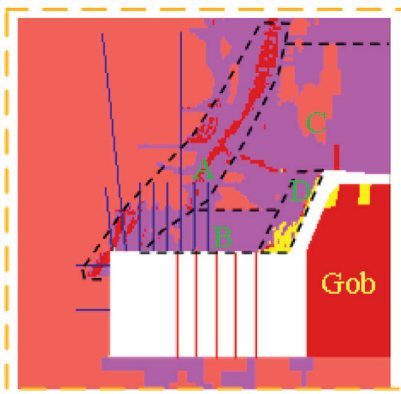

State

$\square$ Elastic

At yield in shear or vol.

Elastic, yield in past

At yield in tension
Initial support design

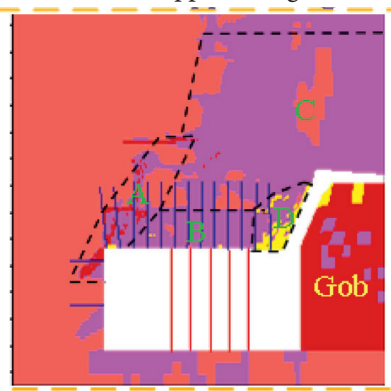

B-B section

Improved support design

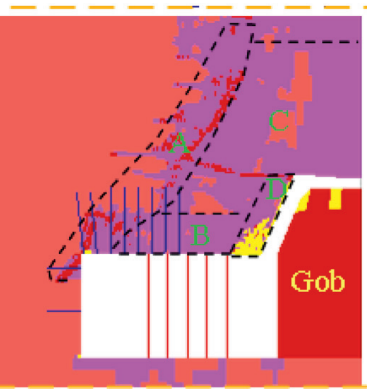

I-A-IS Shear failure zone

I $\overline{\mathrm{B}}-\mathrm{J}$. Plastic failure zone

I $\bar{C}$ ! Partial elastic zone

I- ${ }^{-}$- Tensile failure zone

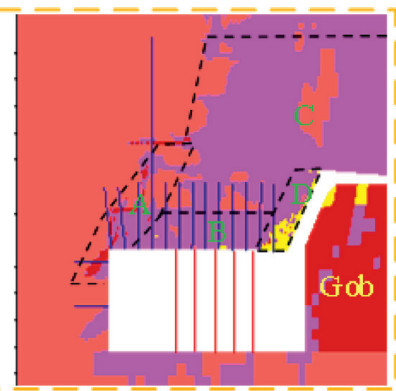

C-C section

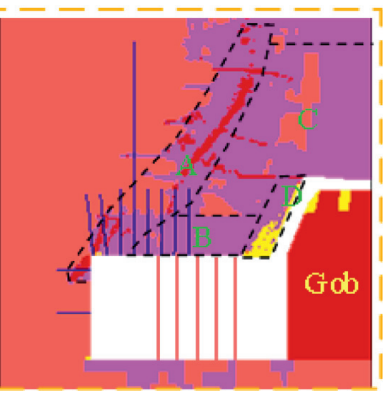

Cable plot

- Rockbolt plot

— Support plot

Figure 19: Plastic zone distribution of the two support designs.

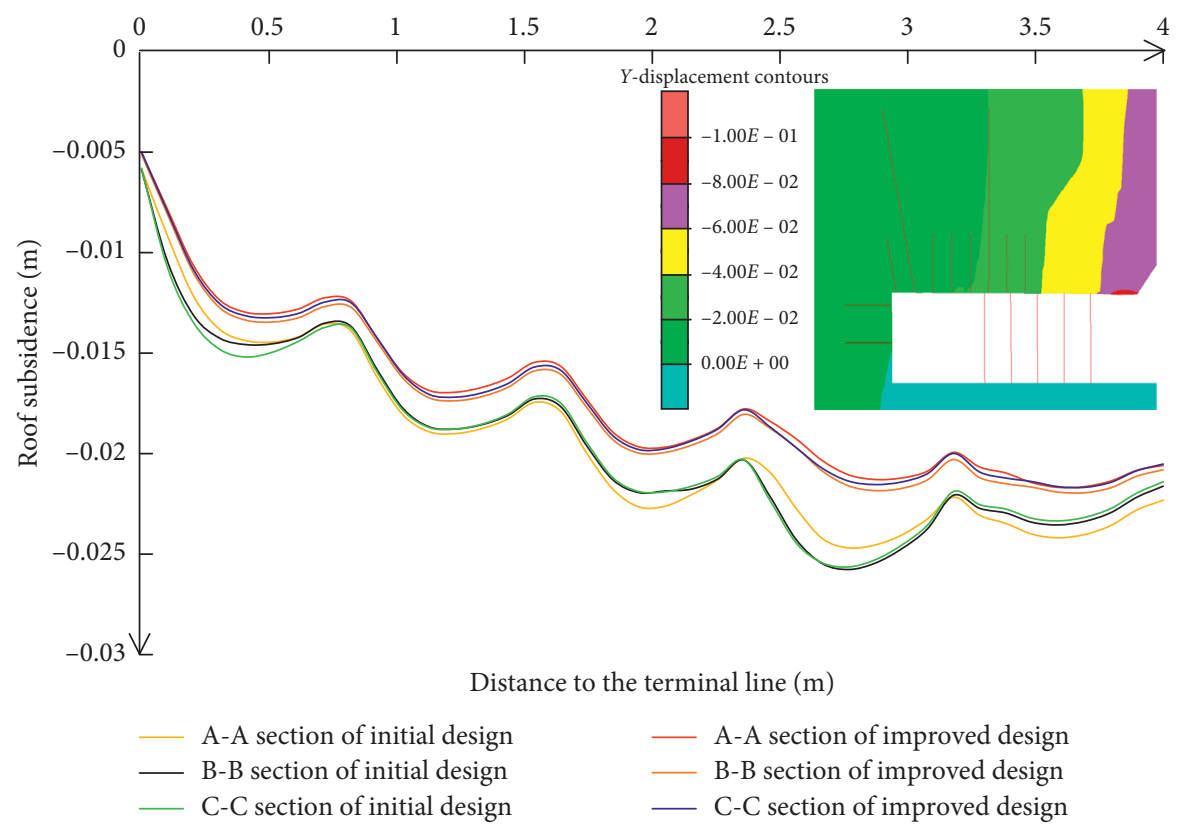

Figure 20: Roof subsidence curves of each section in the two support designs.

improved support design. Figure 21 shows the distributions of the plastic zone after the two support designs were simulated.
Figure 21 shows the following: (1) the roof directly above the recovery roadway underwent integral plastic failure with the two kinds of support designs; (2) plastic failure occurred 


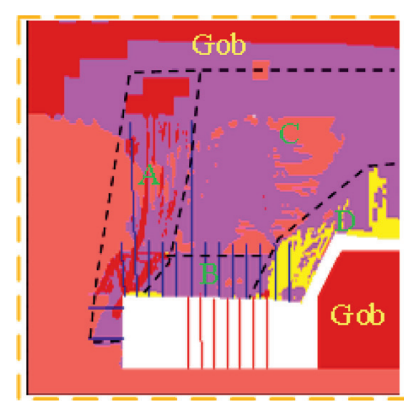

A-A section

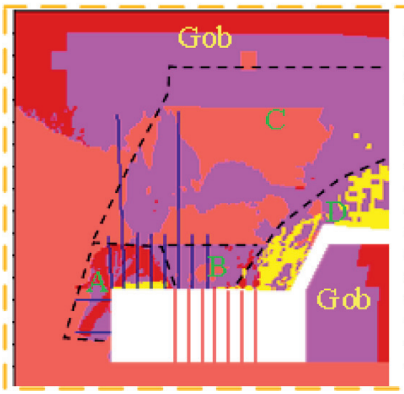

State

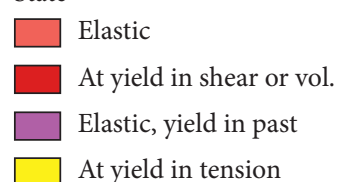

Initial support design

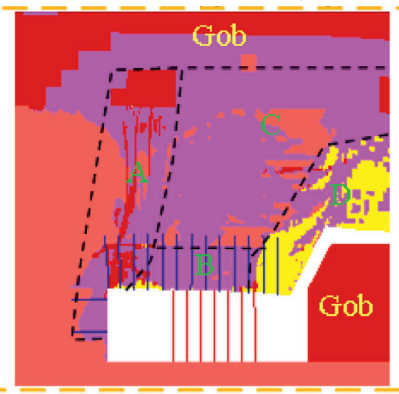

B-B section

Improved support design

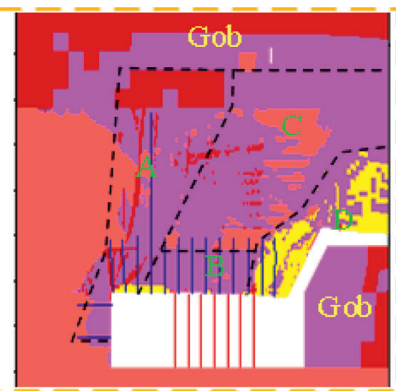

C-C section
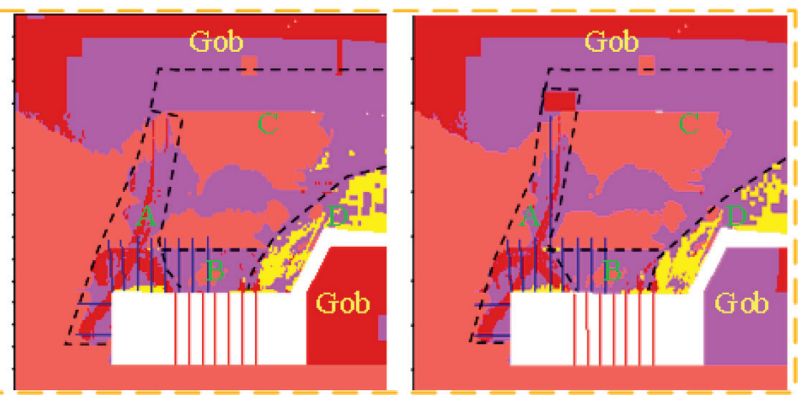

Cable plot

I.A-I Shear failure zone

글 Plastic failure zone

- Rockbolt plot

- Support plot

\section{I}

'] Tensile failure zone

Figure 21: Plastic zone distributions of the two support designs.

in SKS1 above the recovery roadway; and (3) the development range of the plastic zone in the surrounding rock with the improved support design was smaller than that with the initial support design.

The roof subsidence curves of each section in the two support designs are shown in Figure 22.

The roof subsidence of the improved support design was significantly lower than that of the initial support design.

The results showed that the key to the safe and rapid extraction of equipment in shallow seams is to ensure that the support has a reasonable working resistance and to improve the supporting efficiency of the recovery roadway.

\section{Field Application and Discussion}

6.1. Field Application. Based on a combination of theoretical analysis and numerical simulation, the improved support design was adopted to support the recovery roadway during the extraction of equipment in two mines. Because the yield load of the selected support is on the low side, individual hydraulic props were installed on both sides of the support as reinforcement during the extraction of equipment in the \#4 coal seam of the Fengjiata Coal Mine. Table 5 lists the parameters of the individual hydraulic props. The support resistance of the support was raised to approximately $9700 \mathrm{kN}$. Figure 23 shows the construction sites of the recovery roadway in the Liangshuijing Coal Mine and Fengjiata Coal Mine.
The field application results show that the rock pressure appearance and surrounding rock deformation of the recovery roadway can meet the requirements of safe and rapid extraction. Moreover, no roof or support damage occurred during the extraction of equipment. The Liangshuijing Coal Mine and Fengjiata Coal Mine completed the extractions 20 and 14 days ahead of schedule, respectively. The safe and rapid extraction of the longwall face in shallow seams was realized. This success provides a reference for the extraction of equipment under similar geological conditions.

6.2. Discussion. This paper mainly studies the stability control of the rock surrounding recovery roadways to ensure that the supports have reasonable working resistance and to improve the support of the recovery roadways. However, the yield load of the support is generally fixed. When the support cannot meet the roof support requirements, the support resistance of a single hydraulic prop is very limited. If necessary, the roof can be controlled by arranging wooden cribs.

The plastic failure of the roof is inevitable during the extraction of equipment because of the weak lithology. The role of roof rockbolts near the gob is limited, and the rockbolts should be replaced by wire ropes to fix the resin mesh. Therefore, while ensuring the safe extraction of equipment, the construction time can be shortened and the high production and high efficiency of the mine can be realized. 


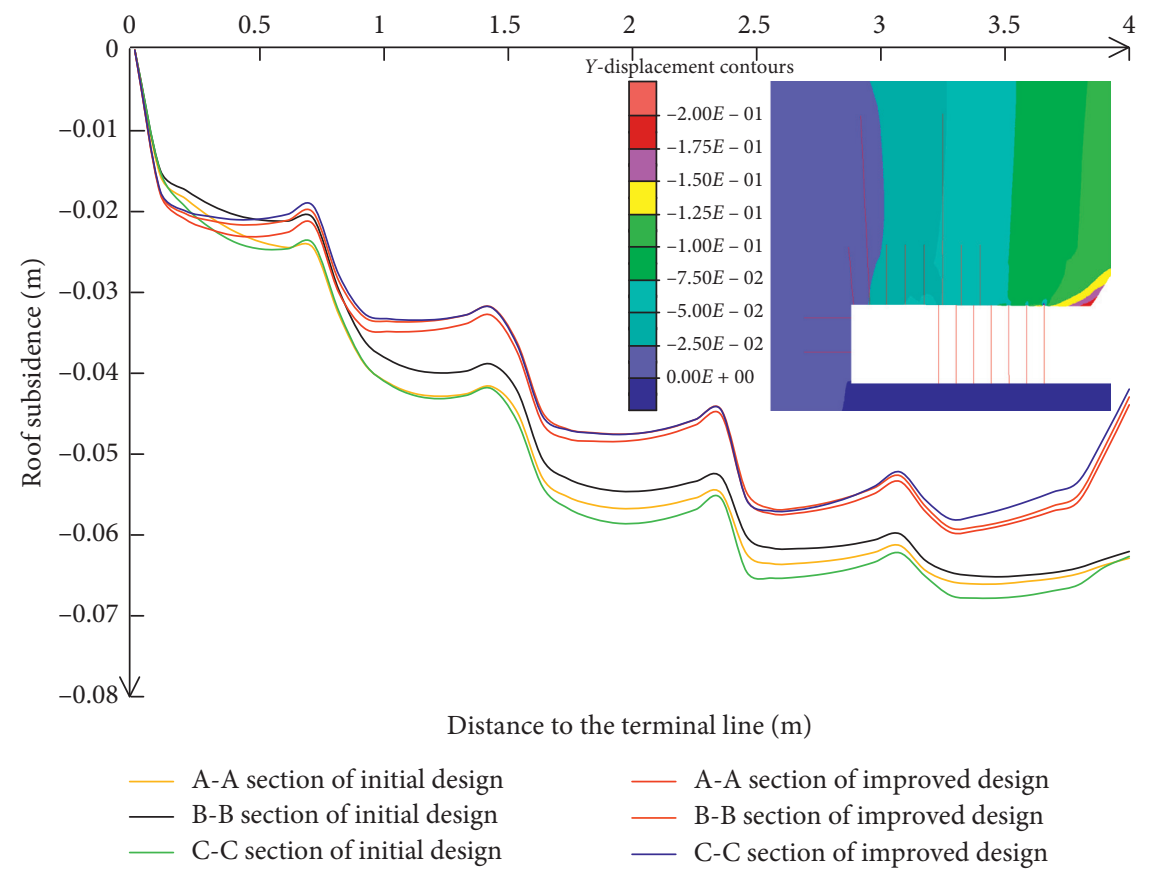

Figure 22: Roof subsidence curves of each section in the two support designs.

TABLE 5: Technical parameters of the individual hydraulic props.

\begin{tabular}{lccc}
\hline Type & Height $(\mathrm{m})$ & Setting load $(\mathrm{kN})$ & Yield load $(\mathrm{kN})$ \\
\hline DZ35-30/110Q & $2.7 \sim 3.5 \mathrm{~m}$ & $144 \sim 188$ & 300 \\
\hline
\end{tabular}

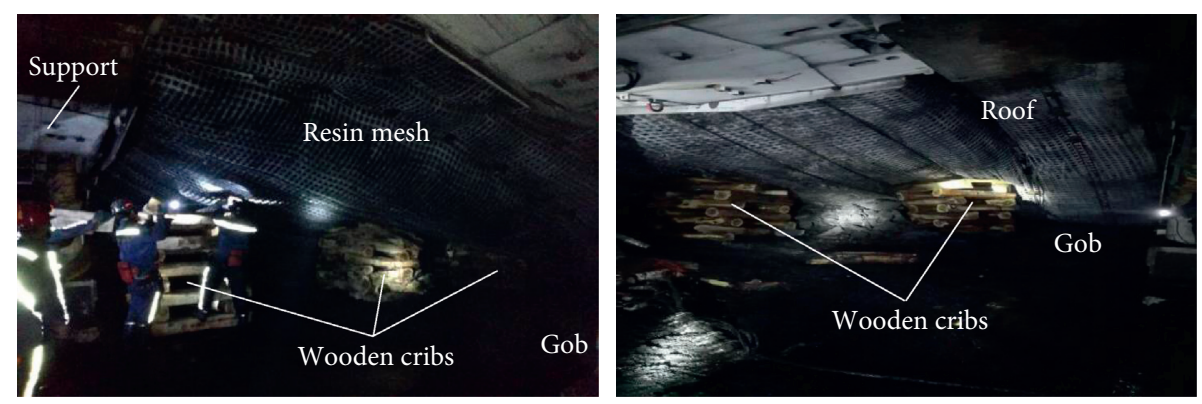

(a)
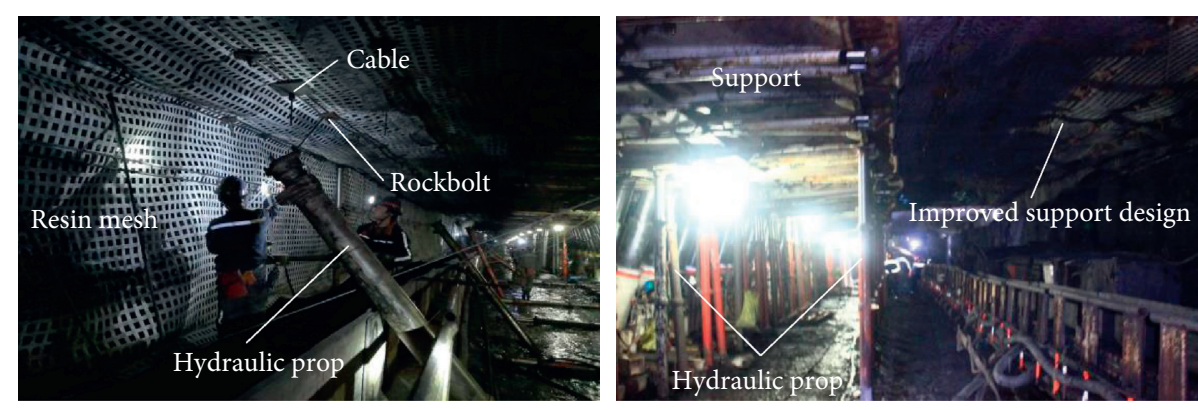

(b)

FIGURE 23: Construction sites of the recovery roadways: (a) \#3-1 coal seam in the Liangshuijing coal mine; (b) \#4 coal seam in the Fengjiata coal mine. 


\section{Conclusions}

This paper mainly studied the stability control of the rock surrounding longwall recovery roadways in shallow seams. The main conclusions are as follows:

(1) Pressure-relief technology can effectively release the accumulated rock pressure in the roof before the extraction of equipment. However, pressure-relief technology is applicable only under certain conditions. The technology should be applied reasonably according to the roof conditions and the law of periodic weighting.

(2) The discriminative approach was proposed for discriminating the breaking form of key strata and the articulated form of broken blocks according to the formation conditions of cantilever-type breaking and the "S-R" stability theory of the voussoir beam structure. On this basis, mechanical models of roof instability were established based on four key stratum structures in the overburden of shallow seams. The calculation methods for the reasonable working resistance of the support were discussed.

(3) According to the actual geological conditions of the two mines, the reasonable working resistance of the support and the reasonable width of the recovery roadway were calculated. Then, the support designs of the recovery roadways were improved based on the development of the plastic zone. The numerical simulation results showed that the development range of the plastic zone in the surrounding rock and the roof subsidence were significantly reduced after the improved support design was applied.

(4) The field application effect of the research results is ideal and can help realize the safe and rapid extraction of longwall faces in shallow seams. The key to the stability control of the rock surrounding longwall recovery roadways in shallow seams is ensuring that the support has a reasonable working resistance, enhancing the supporting efficiency of the roadway and speeding up the extraction of equipment.

\section{Data Availability}

Part of the data used to support the findings of this study are included within the article. Rest of the data used to support the findings of this study are available from the corresponding author upon request.

\section{Conflicts of Interest}

The authors declare that they have no conflicts of interest.

\section{Acknowledgments}

This work was financially supported by the National Key R\&D program of China (No. 2018YFC0604701), the National Natural Science Foundation of China (No. 51974294), the Natural Science Foundation of Jiangsu Province (No. BK20181358), the Independent Research Project of the State Key Laboratory of Coal Resources and Safe Mining, CUMT (No. SKLCRSM19X07), and the Fundamental Research Funds for Central Universities (No. 2019XKQYMS61).

\section{References}

[1] Q. X. Huang, "Ground pressure behavior and definition of shallow seams," China Journal of Rock Mechanics and Engineering, vol. 21, no. 8, pp. 1174-1177, 2002.

[2] R. Singh, P. K. Mandal, A. K. Singh, R. Kumar, J. Maiti, and A. K. Ghosh, "Upshot of strata movement during underground mining of a thick coal seam below hilly terrain," International Journal of Rock Mechanics and Mining Sciences, vol. 45, no. 1, pp. 29-46, 2008.

[3] Z. P. Meng, X. C. Shi, and G. Q. Li, "Deformation failure and permeability of coal-bearing strata during longwall mining," Engineering Geology, vol. 208, pp. 69-80, 2016.

[4] H. Z. Wang, D. S. Zhang, X. F. Wang, and W. Zhang, "Visual exploration of the spatiotemporal evolution law of overburden failure and mining-induced fractures: a case study of the Wangjialing coal mine in China," Minerals, vol. 7, no. 3, p. 35, 2017.

[5] Z. G. Liu, Z. L. Fan, and Y. J. Zhang, "Fracture characteristics of overlying bedrock and clay aquiclude subjected to shallow coal seam mining," Mine Water and the Environment, vol. 38, no. 1, pp. 136-147, 2019.

[6] W. T. Yan, H. Y. Dai, and J. J. Chen, "Surface crack and sand inrush disaster induced by high-strength mining: example from the Shendong coal field, China," Geosciences Journal, vol. 22, no. 2, pp. 347-357, 2018.

[7] J. F. Ju, J. L. Xu, and W. B. Zhu, "Longwall chock sudden closure incident below coal pillar of adjacent upper mined coal seam under shallow cover in the Shendong coalfield," International Journal of Rock Mechanics and Mining Sciences, vol. 77, pp. 192-201, 2015.

[8] P. Huang, F. Ju, K. Jessu, M. Xiao, and S. Guo, "Optimization and practice of support working resistance in fully-mechanized top coal caving in shallow thick seam," Energies, vol. 10, no. 9, p. 1406, 2017.

[9] D. F. Zhu, S. H. Tu, H. S. Tu, and Z. Q. Yang, "Mechanisms of support failure and prevention measures under double-layer room mining gobs-a case study: Shigetai coal mine," International Journal of Mining Science and Technology, vol. 29, no. 6, pp. 955-962, 2019.

[10] C. L. Wang, C. S. Zhang, X. D. Zhao, L. Lin, and S. L. Zhang, "Dynamic structural evolution of overlying strata during shallow coal seam longwall mining," International Journal of Rock Mechanics and Mining Sciences, vol. 103, pp. 20-32, 2018.

[11] D. F. Zhu and S. H. Tu, "Mechanisms of support failure induced by repeated mining under gobs created by two-seam room mining and prevention measures," Engineering Failure Analysis, vol. 82, pp. 161-178, 2017.

[12] Y. Yuan, C.-F. Yuan, C. Zhu, H.-X. Liu, and S.-Z. Wang, "Study on the disaster reduction mechanism of presplitting blasting and reasonable blasting parameters for shallowly buried remnant pillars," Energy Science \& Engineering, vol. 7, no. 6, pp. 2884-2894, 2019.

[13] Q. L. Zou, H. Liu, Y. J. Zhang, Q. Li, J. Fu, and Q. Hu, "Rationality evaluation of production deployment of outburst-prone coal mines: a case study of nantong coal mine in 
Chongqing, China," Safety Science, vol. 122, Article ID 104515, 2020.

[14] H. P. Kang, H. W. Lv, X. Zhang, F. Gao, Z. Wu, and Z. Wang, "Evaluation of the ground response of a pre-driven longwall recovery room supported by concrete cribs," Rock Mechanics and Rock Engineering, vol. 49, no. 3, pp. 1025-1040, 2016.

[15] H.-W. Lv, "The mechanism of stability of pre-driven rooms and the practical techniques," Journal of China Coal Society, vol. 39, no. S1, pp. 50-56, 2014.

[16] C. Zhu, Y. Yuan, Z. S. Chen, Z. H. Liu, and C. F. Yuan, "Study of the stability control of the rock surrounding double-key strata recovery roadways in shallow seams," Advances in Civil Engineering, vol. 2019, Article ID 9801637, 21 pages, 2019.

[17] W. B. Zhu, D. Ren, and M. Chen, "Rational buried depth for regulating roadway application during coal face withdrawal in Shendong mining area," Journal of Mining and Safety Engineering, vol. 32, no. 2, pp. 279-284, 2015.

[18] W. Zhu, J. Xu, and G. Xu, "Mechanism and control of roof fall and support failure incidents occurring near longwall recovery roadways," Journal of the Southern African Institute of Mining and Metallurgy, vol. 117, no. 11, pp. 1063-1072, 2017.

[19] B. F. Wang, B. Liang, K. M. Sun et al., "Research on overlying strata response and control during typical shallow coal seam longwall mining," Rock and Soil Mechanics, vol. 38, no. 9, pp. 2693-2700, 2017.

[20] S. C. Gu, R. B. Huang, J. H. Li, and P. L. Su, "Stability analysis of un-mined coal pillars during the pressure adjustment prior to working face transfixion," Journal of Mining and Safety Engineering, vol. 34, no. 1, pp. 60-66, 2017.

[21] J. L. Xu, W. B. Zhu, X. Z. Wang, and M.-S. Yi, “Classification of key strata structure of overlying strata in shallow coal seam," Journal of China Coal Society, vol. 34, no. 7, pp. 865-870, 2009.

[22] M. G. Qian, X. X. Miao, J. L. Xu, and X. B. Mao, Study of Key Strata Theory in Ground Control, China University of Mining and Technology Press, Xuzhou, China, 2003.

[23] F. T. Wang, S. H. Tu, Y. Yuan, Y. Feng, F. Chen, and H. Tu, "Deep-hole pre-split blasting mechanism and its application for controlled roof caving in shallow depth seams," International Journal of Rock Mechanics and Mining Sciences, vol. 64, pp. 112-121, 2013.

[24] J. G. Ning, J. Wang, L. S. Jiang, N. Jiang, X. Liu, and J. Jiang, "Fracture analysis of double-layer hard and thick roof and the controlling effect on strata behavior: a case study," Engineering Failure Analysis, vol. 81, pp. 117-134, 2017.

[25] M. G. Qian, P. W. Shi, and J. L. Xu, Ground Pressure and Strata Control, China University of Mining and Technology Press, Xuzhou, China, 2010.

[26] J. F. Ju and J. L. Xu, "Structural characteristics of key strata and strata behaviour of a fully mechanized longwall face with 7.0 m height chocks," International Journal of Rock Mechanics and Mining Sciences, vol. 58, pp. 46-54, 2013.

[27] B. Li, Y. P. Liang, and Q. L. Zou, "Determination of working resistance based on movement type of the first subordinate key stratum in a fully mechanized face with large mining height," Energy Science \& Engineering, vol. 7, no. 3, pp. 777-798, 2019.

[28] Y. P. Liang, B. Li, Y. Yuan, Q. L. Zou, and L. X. Jia, “Moving type of key strata and its influence on ground pressure in fully mechanized mining face with large mining height," Journal of China Coal Society, vol. 42, no. 6, pp. 1380-1391, 2017.

[29] Y. P. Liang, B. Li, and Q. L. Zou, "Movement type of the first subordinate key stratum and its influence on strata behavior in the fully mechanized face with large mining height," Arabian Journal of Geosciences, vol. 12, no. 2, p. 31, 2019.

[30] Q. Huang, J. Zhou, L. Ma, and P. Tang, "Double key strata structure analysis of large mining height longwall face in nearly shallow coal seam," Journal of China Coal Society, vol. 42, no. 10, pp. 2504-2510, 2017.

[31] Q.-X. Huang and J.-L. Zhou, "Roof weighting behavior and roof structure of large mining height longwall face in shallow coal seam," Journal of China Coal Society, vol. 41, no. S2, pp. 279-286, 2014.

[32] Z. H. Chen, L. F. Zhang, D. F. Yang, and B. W. Jiang, "Dynamic loading effect of support while roof cutting in shallow coal seam mining," Journal of China Coal Society, vol. 42, no. 2, pp. 322-327, 2017.

[33] L. Yu, Z. Z. Fan, and G. Xu, "Study on the structure characteristics and rock pressure behavior of overlying strata with shallow buried coal seam," Advanced Materials Research, vol. 255-260, pp. 3780-3785, 2011.

[34] X. F. Wang, D. S. Zhang, M. T. Xu, G. Fan, Z. Yang, and D. Qin, "Roof instability mechanism of longwall coalface for sandy soil gullies overlaying shallow seams," Disaster Advances, vol. 6, pp. 260-267, 2013.

[35] C. C. He and J. L. Xu, "Subsidence prediction of overburden strata and surface based on the voussoir beam structure theory," Advances in Civil Engineering, vol. 2018, Article ID 2606108, 13 pages, 2018.

[36] Z. Li, J. L. Xu, J. F. Ju, W. B. Zhu, and J. M. Xu, "The effects of the rotational speed of voussoir beam structures formed by key strata on the rock pressure of stopes," International Journal of Rock Mechanics and Mining Sciences, vol. 108, pp. 67-79, 2018.

[37] Q. L. Zou, H. Liu, Z. H. Cheng et al., "Effect of slot inclination angle and borehole-slot ratio on mechanical property of precracked coal: implications for ECBM recovery using hydraulic slotting," Natural Resources Research, vol. 29, no. 3, pp. 1705-1729, 2019.

[38] P. Wang, H. J. Jia, and P. Q. Zheng, "Sensitivity analysis of bursting liability for different coal-rock combinations based on their inhomogeneous characteristics," Geomatics, Natural Hazards and Risk, vol. 11, no. 1, pp. 149-159, 2020.

[39] J. F. Ju and J. L. Xu, "Surface stepped subsidence related to top-coal caving longwall mining of extremely thick coal seam under shallow cover," International Journal of Rock Mechanics and Mining Sciences, vol. 78, pp. 27-35, 2015.

[40] X. Liu, G. Song, and X. Li, "Classification of roof strata and calculation of powered support loads in shallow coal seams of China," Journal of the Southern African Institute of Mining and Metallurgy, vol. 115, no. 11, pp. 1113-1119, 2015.

[41] P. Wang, L.-S. Jiang, P.-Q. Zheng, G.-P. Qin, and C. Zhang, "Inducing mode analysis of rock burst in fault-affected zone with a hard-thick stratum occurrence," Environmental Earth Sciences, vol. 78, no. 15, p. 467, 2019.

[42] H. J. Zhao, F. S. Ma, J. M. Xu, and J. Guo, "In situ stress field inversion and its application in mining-induced rock mass movement," International Journal of Rock Mechanics and Mining Sciences, vol. 53, pp. 120-128, 2012.

[43] Q. S. Bai, S. H. Tu, F. T. Wang, and C. Zhang, "Field and numerical investigations of gateroad system failure induced by hard roofs in a longwall top coal caving face," International Journal of Coal Geology, vol. 173, pp. 176-199, 2017.

[44] C. Zhang, S. H. Tu, L. Zhang, Q. Bai, Y. Yuan, and F. Wang, "A methodology for determining the evolution law of gob permeability and its distributions in longwall coal mines," Journal 
of Geophysics and Engineering, vol. 13, no. 2, pp. 181-193, 2016.

[45] C. Zhang and L. Zhang, "Permeability characteristics of broken coal and rock under cyclic loading and unloading," Natural Resources Research, vol. 28, no. 3, pp. 1055-1069, 2019.

[46] D. F. Zhu, X. M. Song, H. C. Li, Z. Liu, C. Wang, and Y. Huo, "Cooperative load-bearing characteristics of a pillar group and a gob pile in partially caved areas at shallow depth," Energy Science \& Engineering, vol. 8, no. 1, pp. 89-103, 2019.

[47] D. F. Zhu, Y. H. Wu, Z. H. Liu, X. Dong, and J. Yu, "Failure mechanism and safety control strategy for laminated roof of wide-span roadway," Engineering Failure Analysis, vol. 111, Article ID 104489, 2020. 